\title{
An Accurate Estimate of Monthly Mean Land Surface Temperatures from MODIS Clear-Sky Retrievals 0
}

\author{
Xuelong Chen And Zhongbo Su \\ Faculty of Geo-Information Science and Earth Observation, University of Twente, Enschede, Netherlands \\ YAOMING MA \\ Key Laboratory of Tibetan Environment Changes and Land Surface Processes, Institute of Tibetan Plateau \\ Research, and Center for Excellence in Tibetan Plateau Earth Sciences, Chinese Academy of Sciences, Beijing, China

\section{JAMES CLEVERLY} \\ TERN OzFlux Network, and School of Life Sciences, University of Technology Sydney, Broadway, \\ New South Wales, Australia

\section{MICHAEL LIDDELL} \\ TERN SuperSite Network, and Centre for Tropical Environmental and Sustainability Science, James Cook \\ University, Cairns, Queensland, Australia
}

(Manuscript received 9 January 2017, in final form 16 August 2017)

\begin{abstract}
MODIS thermal sensors can provide us with global land surface temperature (LST) several times each day, but have difficulty in obtaining information from the land surface in cloudy situations. As a result, the monthly day or night LST products [Terra monthly day LST (TMD), Terra monthly night LST (TMN), Aqua monthly day LST (AMD), and Aqua monthly night LST (AMN)] are the average LST values calculated over a variable number of clear-sky days in a month. Is it possible to derive an accurate estimate of monthly mean LST based on averaging of the multidaily overpasses of MODIS sensors? In situ ground measurements and ERA-Interim reanalyses data, both of which provide continuous information in either clear or cloudy conditions, have been used to validate the approach. Using LST measurements from 156 ground flux towers, it was found that the three mean values $\operatorname{LST}_{(\overline{\mathrm{AMD}, \mathrm{AMN}})}, \mathrm{LST}_{(\overline{\mathrm{TMD}, \mathrm{TMN}})}$, and $\mathrm{LST}_{(\overline{\mathrm{AMD}, \mathrm{AMN}, \mathrm{TMD}, \mathrm{TMN})}}$ (mean biases of 0.19, 0.59, and $0.40 \mathrm{~K}$, respectively) can all provide a reliable estimate of all-sky monthly mean LST. Of the three means, we recommend the use of $\mathrm{LST}_{(\overline{\mathrm{AMD}, A M N, T M D, T M N})}$ for monthly mean LST in climate studies as it provides the most complete coverage. When retrievals from either Terra or Aqua are not available, then either $\mathrm{LST}_{(\overline{\mathrm{AMD}, \mathrm{AMN}})}$ or $\mathrm{LST}_{(\overline{\mathrm{TMD}, \mathrm{TMN}})}$ may be used to fill the gaps. The intrinsic error in the MODIS monthly mean LST cannot be explained from monthly mean view time, view angle, and clear-sky ratio. MODIS monthly LST calculated using this approach $\operatorname{LST}_{(\overline{\mathrm{AMD}, \mathrm{AMN}, \mathrm{TMD}, \mathrm{TMN}})}(\mathrm{RMSE}=2.65$, mean bias $< \pm 1 \mathrm{~K})$ will have wide applicability for climate studies and numerical model evaluation.
\end{abstract}

\section{Introduction}

Land surface temperature (LST), as a key variable at the land-atmosphere interface, may be derived from satellite

Supplemental information related to this paper is available at the Journals Online website: https://doi.org/10.1175/ JHM-D-17-0009.s1.

Corresponding author: Xuelong Chen, x.chen@utwente.nl sensor systems to provide global coverage (Li et al. 2013). Remote sensing LST usage is growing within the fields of meteorology and climatology (Tomlinson et al. 2011) and in studying urban heat island effects (Imhoff et al. 2010). LST obtained by satellite remote sensing provides information with sufficient spatial resolution and global coverage to reveal new information about the land surface energy balance (Jin and Robert 2010).

Satellite-based LST retrievals are routinely derived from infrared sensors on both polar-orbiting and 
geostationary orbiting satellites (Freitas et al. 2013; Prata 1993; Sobrino and Romaguera 2004; Sun and Pinker 2003; Wan and Dozier 1996; Wu et al. 2015). High temporal sampling of LST is achievable with geostationary satellites, but the spatial resolution is relatively coarse. Polar-orbiting satellites provide a more uniform global view of the earth, with similar or even better accuracy and higher spatial resolution in LST (Inamdar and French 2009). Polar-orbiting thermal sensors pass twice over the same equatorial area and increase to more than 8 times over the polar region in each 24-h period, covering a vast swath with a width of thousands of kilometers. The Moderate Resolution Imaging Spectroradiometer (MODIS), an instrument platform on NASA's Terra and Aqua polar-orbiting satellites, has successfully provided estimates of surface temperature for the past decades at a spatial resolution of $1000 \mathrm{~m}$, a considerably higher resolution than that found in LST products from geostationary satellites (Wan et al. 2004). MOD11C3 [which includes Terra monthly day LST (TMD) and Terra monthly night LST (TMN)] and MYD11C3 [which includes Aqua monthly day LST (AMD) and Aqua monthly night LST (AMN)] monthly day and night products are provided at $0.05^{\circ} \times 0.05^{\circ}$ (latitude by longitude) resolution for the purpose of climate modeling studies (Wan and Li 2008). The two products are essentially spatially and temporally continuous with only a few spatial gaps when extremely cloudy conditions persist in a $0.05^{\circ} \times 0.05^{\circ}$ area for a month period (Wan 2006). An important issue is how to use the monthly day and monthly night LST (MOD11C3 and MYD11C3) together in an effective way, and is it possible to produce a monthly mean global LST of high accuracy from these datasets? To date, no studies have investigated the differences between monthly day LST, monthly night LST, and monthly LST; in contrast, there are many studies that use either monthly day or monthly night LST to assist in climate change analyses, although often without a clear justification for the choice of the particular monthly LST products used (Qin et al. 2009; Sobrino and Julien 2013; Wang et al. 2008; Zhang et al. 2014). Monthly mean LST from satellite observation is not only appropriate for general climate trend studies but also has a broad application in spatial-temporal validation of large-scale land surface models (Koch et al. 2016). MODIS LST is only available in clear-sky conditions. So the monthly day and night LST values in the MOD11C3/MYD11C3 product are the average LST values over a variable number of clear-sky days in one month. The questions in this study are, Can the clear-sky monthly day and monthly night LST datasets (MOD11C3 and MYD11C3) produce a global all-sky monthly mean LST of sufficient accuracy to be of use in the climate trend and modeling communities, and can the underlying variability in clear-sky LST samples have an influence on the accuracy of the calculated monthly mean LST?

\section{Methodology and datasets processing}

\section{a. Methodology}

Evaluation of LST algorithms is complicated because LST is highly variable in space and time. Here both in situ flux tower measurements and ERA-Interim reanalysis data (Dee et al. 2011) were used for the evaluation, as both datasets have different characteristics. Ground station in situ measurements provided high-frequency, highaccuracy data. While these data provided the reference values, they are not strictly directly comparable with the satellite data because of the spatial resolution of satellites (Pinker et al. 2009) and the fact that the flux stations are at discrete locations. Interim reanalysis data can provide a spatially complete and coherent record of the LST by using data assimilation, observation, and forecast models, and they have been widely used (Jiménez-Muñoz et al. 2013; Zhou et al. 2012).

The research question posited in this paper is whether the mean LST of TMD and TMN (LST $(\overline{\mathrm{TMD}, \mathrm{TMN})})$; the mean LST of AMD and AMN (LST $(\overline{\mathrm{AMD}, \mathrm{AMN}})$ ); and the mean LST of TMD, TMN, AMD, and AMN

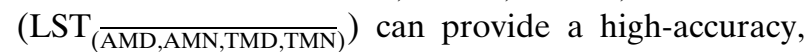
global, all-sky monthly mean LST at 5-km resolution. Hourly, high-frequency LST measurements at 156 flux tower stations (the station locations are shown in Table 1) have been collated by this study from FluxNet (Baldocchi et al. 2001) and processed to all-sky monthly mean LST. The $\operatorname{LST}_{(\overline{\mathrm{TMD}, \mathrm{TMN}})}, \mathrm{LST}_{(\overline{\mathrm{AMD}, \mathrm{AMN}})}$, and $\left.\operatorname{LST}_{(\overline{A M D}, A M N, T M D, T M N}\right)$ were then evaluated against the in situ all-sky monthly mean LST values.

There are quite a few gaps in TMD, TMN, AMD, and AMN products that are due primarily to cloud contamination. To obtain accurate mean values for LST the following method was used: $\operatorname{LST}_{(\overline{\mathrm{TMD}, \mathrm{TMN}})}$ was calculated only when both TMD and TMN were not null. The same rule was applied to $\mathrm{LST}_{(\overline{\mathrm{AMD}, \mathrm{AMN}})}$. Parameter $\operatorname{LST}_{(\overline{A M D, A M N, T M D, T M N})}$ was calculated from either $\operatorname{LST}_{(\overline{\mathrm{TMD}, \mathrm{TMN}})}$ or LST $(\overline{\mathrm{AMD}, \mathrm{AMN})}$ when one of the two was null. The composite mean LST $(\overline{\mathrm{AMD}, \mathrm{AMN}, \mathrm{TMD}, \mathrm{TMN})})$ was null only when both $\operatorname{LST}_{(\overline{\mathrm{TMD}, \mathrm{TMN}})}$ and $\mathrm{LST}_{(\overline{\mathrm{AMD}, \mathrm{AMN}})}$ were null, as this reduced the number of gaps in global mean monthly LST substantially.

ERA-Interim is the latest global atmospheric reanalysis produced by the European Centre for MediumRange Weather Forecasts (ECMWF; Dee et al. 2011). ERA-Interim data provide a global view of LST in a physically consistent framework. Monthly means of land skin temperatures of ERA-Interim were used to assess 
TABLE 1. Statistical values derived from comparison between the pixel in which the flux site is located and the flux site measurement. CSR means clear-sky ratio, $\mathrm{RE}$ is relative error, and $\mathrm{SD}$ is standard deviation.

\begin{tabular}{|c|c|c|c|c|c|c|c|c|}
\hline & Site & Lat $\left(^{\circ}\right)$ & Lon $\left(^{\circ}\right)$ & $\begin{array}{c}\text { RMSE } \\
(\mathrm{K})\end{array}$ & $\begin{array}{l}\mathrm{RE} \\
(\mathrm{K})\end{array}$ & $R^{2}$ & $\mathrm{SD}$ & CSR \\
\hline 1 & Qomolangma & 28.35821 & 86.94964 & 3.31 & 1.74 & 0.906 & 2.84 & 0.84 \\
\hline 2 & Namco & 30.7699 & 90.9636 & 4.16 & 0.23 & 0.852 & 4.19 & 0.73 \\
\hline 3 & Wenjiang & 30.42 & 103.5 & 1.53 & 1.02 & 0.968 & 1.16 & 0.19 \\
\hline 4 & Maqu & 33.8872 & 102.1406 & 2.71 & 2.24 & 0.981 & 1.58 & 0.66 \\
\hline 5 & Ali & 33.39056 & 79.7035 & 2.02 & 0.93 & 0.981 & 1.97 & 0.84 \\
\hline 6 & Bijie & 31.36866 & 91.89869 & 3.27 & 0.89 & 0.949 & 3.19 & 0.71 \\
\hline 7 & Miyun & 40.6038 & 117.3233 & 1.99 & 0.15 & 0.987 & 2.02 & 0.67 \\
\hline 8 & Daxing & 39.6213 & 116.427 & 1.45 & 0.21 & 0.984 & 1.46 & 0.52 \\
\hline 9 & Guantao & 36.515 & 115.1274 & 1.65 & 0.99 & 0.989 & 1.34 & 0.47 \\
\hline 10 & Yucheng & 36.95 & 116.6 & 1.41 & 1.03 & 0.990 & 0.99 & 0.49 \\
\hline 11 & Dongtan & 31.5169 & 121.9717 & 1.85 & -1.36 & 0.984 & 1.28 & 0.49 \\
\hline 12 & SACOL & 35.95 & 104.133 & 1.20 & 0.45 & 0.990 & 1.14 & 0.61 \\
\hline 13 & Gaize & 32.09 & 84.25 & 2.11 & 0.68 & 0.959 & 2.04 & 0.82 \\
\hline 14 & Tanggula & 32.5833 & 91.8667 & 2.74 & -1.23 & 0.949 & 2.56 & 0.75 \\
\hline 15 & Changbaishan & 42.4025 & 127.09 & 2.15 & 0.15 & 0.982 & 2.17 & 0.58 \\
\hline 16 & Dangxiong & 30.496 & 91.05833 & 3.19 & 0.00 & 0.912 & 3.26 & 0.71 \\
\hline 17 & Dinghushan & 23.16667 & 112.5333 & 1.27 & 0.14 & 0.967 & 1.28 & 0.38 \\
\hline 18 & Haibei & 37.66528 & 101.3311 & 2.45 & 2.14 & 0.984 & 1.20 & 0.69 \\
\hline 19 & Neimeng & 43.5 & 116.68 & 2.59 & 2.07 & 0.994 & 1.59 & 0.66 \\
\hline 20 & Qianyanzhou & 26.73333 & 115.0667 & 3.85 & 1.67 & 0.782 & 3.52 & 0.35 \\
\hline 21 & Xishuangbanna & 21.95 & 101.02 & 2.33 & 1.61 & 0.784 & 1.71 & 0.52 \\
\hline 22 & Qomolangma & 33.06 & 91.94 & 1.66 & -0.17 & 0.973 & 1.70 & 0.74 \\
\hline 23 & Namco & 31.93 & 91.71 & 4.97 & -4.52 & 0.954 & 2.12 & 0.70 \\
\hline 24 & ARM_SGP_Main & 36.6058 & -97.488 & 3.15 & 2.21 & 0.951 & 2.26 & 0.59 \\
\hline 25 & $\begin{array}{l}\text { ARM_USDA_UNL_OSU_- } \\
\text { Woodward_Switchgrass_1 }\end{array}$ & 36.4267 & -99.42 & 1.68 & 0.10 & 0.974 & 1.72 & 0.62 \\
\hline 26 & $\begin{array}{l}\text { ARM_USDA_UNL_OSU_- } \\
\text { Woodward_Switchgrass_2 }\end{array}$ & 36.6358 & -99.597 & 1.55 & 0.14 & 0.979 & 1.58 & 0.64 \\
\hline 27 & $\begin{array}{l}\text { Anaktuvuk_River_Moderate_ } \\
\text { Burn }\end{array}$ & 68.95 & 150.21 & 4.59 & -1.89 & 0.694 & 4.36 & 0.77 \\
\hline 28 & $\begin{array}{l}\text { Anaktuvuk_River_Severe_ } \\
\text { Burn }\end{array}$ & 68.99 & 150.28 & 4.95 & -1.63 & 0.369 & 4.88 & 0.75 \\
\hline 29 & Audubon_Research_Ranch & 31.5907 & -110.5 & 3.29 & 3.14 & 0.985 & 1.00 & 0.79 \\
\hline 30 & Black_Hills & 44.158 & -103.65 & 2.12 & 1.64 & 0.980 & 1.35 & 0.65 \\
\hline 31 & Bondville & 40.0062 & -88.2904 & 2.44 & 1.74 & 0.975 & 1.73 & 0.48 \\
\hline 32 & Bondville_Companion_Site & 40.0061 & -88.2918 & 4.03 & 3.18 & 0.938 & 2.51 & 0.48 \\
\hline 33 & Brookings & 44.3453 & -96.8362 & 2.33 & 1.33 & 0.985 & 1.93 & 0.57 \\
\hline 34 & Canaan_Valley & 39.0633 & -79.4208 & 4.12 & 2.18 & 0.850 & 3.53 & 0.45 \\
\hline 35 & Chestnut_Ridge & 35.9311 & -84.3324 & 1.41 & 0.32 & 0.970 & 1.38 & 0.58 \\
\hline 36 & Cottonwood & 43.95 & -101.846 & 2.62 & 2.06 & 0.983 & 1.65 & 0.59 \\
\hline 37 & Duke_Forest_Hardwoods & 35.9736 & -79.1004 & 1.35 & 0.66 & 0.980 & 1.19 & 0.58 \\
\hline 38 & Duke_Forest_Loblolly_Pine & 35.9782 & -79.0942 & 1.38 & 0.79 & 0.981 & 1.14 & 0.58 \\
\hline 39 & Duke_Forest_Open_Field & 35.9712 & -79.0934 & 1.71 & 0.77 & 0.977 & 1.54 & 0.58 \\
\hline 40 & Flagstaff_Managed_Forest & 35.1426 & -111.727 & 1.76 & 0.95 & 0.979 & 1.49 & 0.80 \\
\hline 41 & Flagstaff_Unmanaged_Forest & 35.089 & -111.762 & 1.94 & 1.53 & 0.986 & 1.20 & 0.80 \\
\hline 42 & Flagstaff_Wildfire & 35.4454 & -111.771 & 1.49 & 0.83 & 0.985 & 1.24 & 0.81 \\
\hline 43 & $\begin{array}{l}\text { Florida_Everglades_ } \\
\text { Shark_River_Slough_ } \\
\text { Mangrove_Forest }\end{array}$ & 25.3646 & -81.0779 & 1.72 & -1.52 & 0.961 & 0.82 & 0.66 \\
\hline 44 & Fort_Peck & 48.3077 & -105.101 & 3.08 & 1.76 & 0.969 & 2.55 & 0.59 \\
\hline 45 & $\begin{array}{l}\text { Freeman_Ranch_Mesquite_ } \\
\text { Juniper }\end{array}$ & 29.9495 & -97.9962 & 1.18 & 0.88 & 0.985 & 0.82 & 0.56 \\
\hline 46 & GLEES & 41.3644 & -106.239 & 1.91 & -0.74 & 0.986 & 1.78 & 0.75 \\
\hline 47 & Goodwin_Creek & 34.2547 & -89.7735 & 1.61 & 0.23 & 0.969 & 1.61 & 0.63 \\
\hline 48 & $\begin{array}{l}\text { Heritage_Land_Conservancy_ } \\
\text { Pinyon_Juniper_Woodland }\end{array}$ & 34.4384 & -106.237 & 3.93 & 3.57 & 0.990 & 1.79 & 0.81 \\
\hline
\end{tabular}


TABLE 1. (Continued)

\begin{tabular}{|c|c|c|c|c|c|c|c|c|}
\hline & Site & Lat $\left(^{\circ}\right)$ & Lon $\left(^{\circ}\right)$ & $\begin{array}{l}\text { RMSE } \\
(\mathrm{K})\end{array}$ & $\begin{array}{l}\mathrm{RE} \\
(\mathrm{K})\end{array}$ & $R^{2}$ & $\mathrm{SD}$ & CSR \\
\hline 49 & $\begin{array}{l}\text { Howland_Forest_East_ } \\
\text { Tower_Harvest_Site }\end{array}$ & 45.2072 & -68.725 & 1.92 & -1.22 & 0.983 & 1.51 & 0.50 \\
\hline 50 & Howland_Forest_Main & 45.2041 & -68.7402 & 1.92 & -1.22 & 0.983 & 1.51 & 0.50 \\
\hline 51 & Howland_Forest_West_Tower & 45.2091 & -68.747 & 1.92 & -1.22 & 0.983 & 1.51 & 0.50 \\
\hline 52 & Ivotuk & 68.4865 & -155.75 & 4.97 & -3.05 & 0.967 & 3.97 & 0.71 \\
\hline 53 & Kansas_Field_Station & 39.0561 & -95.1907 & 1.54 & 0.38 & 0.987 & 1.56 & 0.57 \\
\hline 54 & Kendall_Grassland & 31.7365 & -109.941 & 2.57 & 2.36 & 0.987 & 1.03 & 0.78 \\
\hline 55 & $\begin{array}{l}\text { LBA_Tapajos_KM83_ } \\
\text { Logged_Forest }\end{array}$ & -3.018 & -54.9714 & 2.97 & -2.91 & 0.809 & 0.57 & 0.34 \\
\hline 56 & Lucky_Hills_Shrubland & 31.7438 & -110.05 & 1.29 & 1.14 & 0.993 & 0.64 & 0.80 \\
\hline 57 & Marys_River_Fir_Site & 44.6465 & -123.55 & 1.92 & -0.36 & 0.983 & 1.91 & 0.58 \\
\hline 58 & Mead_Irrigated & 41.1651 & -96.476 & 2.63 & 2.01 & 0.978 & 1.71 & 0.55 \\
\hline 59 & Mead_Irrigated_Rotation & 41.1649 & -96.47 & 2.57 & 1.96 & 0.978 & 1.67 & 0.55 \\
\hline 60 & Mead_Rainfed & 41.1797 & -96.439 & 2.55 & 1.99 & 0.980 & 1.60 & 0.55 \\
\hline 61 & Metolius_Intermediate_Pine & 44.4523 & -121.55 & 3.49 & 1.84 & 0.969 & 2.99 & 0.68 \\
\hline 62 & Metolius_Second_Young_Pine & 44.3154 & -121.6 & 1.54 & 0.63 & 0.985 & 1.50 & 0.68 \\
\hline 63 & Metolius_Young_Pine_Burn & 44.3232 & -121.6 & 1.81 & 0.56 & 0.985 & 1.84 & 0.68 \\
\hline 64 & Missouri_Ozark & 38.7441 & -92.2 & 1.69 & 1.33 & 0.987 & 1.05 & 0.55 \\
\hline 65 & Morgan_Monroe_State_Forest & 39.3232 & -86.413 & 2.04 & -1.51 & 0.978 & 1.38 & 0.50 \\
\hline 66 & Niwot_Ridge & 40.0329 & -105.54 & 2.38 & 1.70 & 0.979 & 1.68 & 0.74 \\
\hline 67 & North_Carolina_Clearcut & 35.8115 & -76.711 & 1.06 & 0.41 & 0.987 & 0.99 & 0.58 \\
\hline 68 & North_Carolina_Loblolly_Pine & 35.8031 & -76.667 & 1.45 & 0.57 & 0.968 & 1.34 & 0.57 \\
\hline 69 & Santa_Rita_Creosote & 31.9083 & -110.839 & 2.86 & 2.48 & 0.968 & 1.46 & 0.79 \\
\hline 70 & Santa_Rita_Mesquite_Savanna & 31.8214 & -110.866 & 3.31 & 3.03 & 0.989 & 1.33 & 0.78 \\
\hline 71 & Sevilleta_Desert_Grassland & 34.3623 & -106.701 & 3.53 & 3.25 & 0.989 & 1.38 & 0.79 \\
\hline 72 & Sevilleta_Desert_Shrubland & 34.3349 & -106.744 & 3.21 & 2.95 & 0.992 & 1.28 & 0.77 \\
\hline 73 & $\begin{array}{l}\text { Silas_Little_Experimental_ } \\
\text { Forest }\end{array}$ & 39.9137 & -74.596 & 0.98 & -0.53 & 0.991 & 0.84 & 0.53 \\
\hline 74 & Sioux_Falls_Portable & 43.2408 & -96.902 & 3.90 & 1.48 & 0.913 & 3.68 & 0.55 \\
\hline 75 & Tablelands_Juniper_Savanna & 34.4255 & -105.861 & 4.31 & 3.79 & 0.952 & 2.08 & 0.75 \\
\hline 76 & UMBS & 45.5598 & -84.7138 & 2.59 & -1.59 & 0.991 & 2.06 & 0.57 \\
\hline 77 & Vaira_Ranch & 38.4067 & -120.95 & 2.41 & 0.46 & 0.940 & 2.38 & 0.76 \\
\hline 78 & Valles_Caldera_Mixed_Conifer & 35.8884 & -106.532 & 2.31 & 0.33 & 0.960 & 2.35 & 0.79 \\
\hline 79 & Valles_Caldera_Ponderosa_Pine & 35.8624 & -106.597 & 1.37 & -0.37 & 0.980 & 1.35 & 0.77 \\
\hline 80 & Walker_Branch & 35.9588 & -84.2874 & 2.74 & 1.39 & 0.897 & 2.38 & 0.57 \\
\hline 81 & Willow_Creek & 45.9059 & -90.0799 & 3.23 & -1.89 & 0.958 & 2.65 & 0.52 \\
\hline 82 & Wind_River_Crane_Site & 45.8205 & -121.951 & 2.68 & -1.98 & 0.972 & 1.82 & 0.56 \\
\hline 83 & Adelaide River site & -13.077 & 131.118 & 1.90 & -1.34 & 0.598 & 1.40 & 0.53 \\
\hline 84 & Alice Springs & -22.283 & 133.249 & 3.02 & 2.74 & 0.969 & 1.29 & 0.75 \\
\hline 85 & Arcturus, in central Queensland & -23.8587 & 148.4746 & 2.17 & 1.82 & 0.964 & 1.20 & 0.64 \\
\hline 86 & Calperum & -34.0021 & 140.5891 & 2.13 & 0.94 & 0.984 & 1.93 & 0.74 \\
\hline 87 & Daintree & -16.2382 & 145.4272 & 3.22 & -3.05 & 0.797 & 1.04 & 0.56 \\
\hline 88 & Daly Pasture & -17.1507 & 133.3502 & 3.99 & 3.29 & 0.746 & 2.27 & 0.64 \\
\hline 89 & Daly Regrowth & -14.1592 & 131.3881 & 2.10 & -1.51 & 0.774 & 1.49 & 0.57 \\
\hline 90 & DalyUncleared & -14.1592 & 131.3881 & 1.87 & -1.32 & 0.809 & 1.35 & 0.57 \\
\hline 91 & Dry River & -15.2588 & 132.3706 & 3.48 & -3.17 & 0.881 & 1.45 & 0.59 \\
\hline 92 & Gingin & -31.375 & 115.65 & 1.54 & 0.40 & 0.970 & 1.56 & 0.82 \\
\hline 93 & Great Western Woodlands & -30.1914 & 120.6542 & 3.47 & 2.63 & 0.957 & 2.37 & 0.79 \\
\hline 94 & Otway & -38.5323 & 142.8168 & 1.54 & -0.47 & 0.966 & 1.48 & 0.63 \\
\hline 95 & Red Dirt Melon Farm & -14.5636 & 132.4776 & 1.33 & -0.85 & 0.904 & 1.05 & 0.57 \\
\hline 96 & Riggs Creek & -36.656 & 145.576 & 1.70 & 0.77 & 0.985 & 1.54 & 0.69 \\
\hline 97 & SturtPlains & -17.1507 & 133.3502 & 1.76 & -0.21 & 0.884 & 1.76 & 0.64 \\
\hline 98 & Ti Tree East & -22.287 & 133.64 & 1.83 & 1.71 & 0.995 & 0.66 & 0.78 \\
\hline 99 & Tumbarumba, Australia & -35.6566 & 148.1516 & 1.59 & 1.47 & 0.987 & 0.61 & 0.67 \\
\hline 100 & Whroo & -36.6732 & 145.0294 & 2.24 & 1.06 & 0.989 & 2.02 & 0.71 \\
\hline 101 & ATNeu & 47.11667 & 11.3175 & 3.06 & -1.96 & 0.929 & 2.37 & 0.64 \\
\hline 102 & BEBra & 51.30917 & 4.520555 & 1.88 & -0.83 & 0.972 & 1.70 & 0.46 \\
\hline
\end{tabular}


TABLE 1. (Continued)

\begin{tabular}{|c|c|c|c|c|c|c|c|c|}
\hline & Site & Lat $\left(^{\circ}\right)$ & Lon $\left(^{\circ}\right)$ & $\begin{array}{l}\text { RMSE } \\
(\mathrm{K})\end{array}$ & $\begin{array}{l}\mathrm{RE} \\
(\mathrm{K})\end{array}$ & $R^{2}$ & $\mathrm{SD}$ & CSR \\
\hline 103 & BELon & 50.55219 & 4.744772 & 2.32 & -1.24 & 0.946 & 2.01 & 0.48 \\
\hline 104 & CHLae & 47.47808 & 8.365 & 4.09 & 3.62 & 0.980 & 1.92 & 0.48 \\
\hline 105 & CHOe1 & 47.28583 & 7.731945 & 2.33 & -1.76 & 0.973 & 1.54 & 0.49 \\
\hline 106 & $\mathrm{CHOe} 2$ & 47.2863 & 7.734334 & 4.04 & -1.27 & 0.780 & 3.92 & 0.49 \\
\hline 107 & CZBK2 & 49.49443 & 18.54285 & 2.68 & 1.26 & 0.867 & 2.39 & 0.48 \\
\hline 108 & CZWet & 49.02465 & 14.77035 & 1.91 & 0.37 & 0.971 & 1.90 & 0.48 \\
\hline 109 & DEGeb & 51.1001 & 10.9143 & 1.56 & 0.13 & 0.979 & 1.56 & 0.49 \\
\hline 110 & DEGri & 50.94947 & 13.51252 & 1.66 & 0.08 & 0.970 & 1.68 & 0.45 \\
\hline 111 & DEHai & 51.07917 & 10.453 & 1.76 & -0.77 & 0.976 & 1.59 & 0.45 \\
\hline 112 & DEKli & 50.89288 & 13.52251 & 2.08 & -0.71 & 0.966 & 1.97 & 0.48 \\
\hline 113 & DEMe2 & 51.27537 & 10.65555 & 1.67 & -0.73 & 0.984 & 1.52 & 0.44 \\
\hline 114 & DEMeh & 51.27531 & 10.65547 & 1.71 & -0.78 & 0.984 & 1.54 & 0.44 \\
\hline 115 & DETha & 50.96361 & 13.56694 & 2.53 & -1.66 & 0.978 & 1.92 & 0.49 \\
\hline 116 & DEWet & 50.4535 & 11.45753 & 1.48 & 0.31 & 0.979 & 1.46 & 0.45 \\
\hline 117 & DKRis & 55.53028 & 12.09722 & 1.78 & 0.62 & 0.962 & 1.70 & 0.52 \\
\hline 118 & DKSor & 55.48587 & 11.64464 & 2.57 & -1.63 & 0.973 & 2.00 & 0.51 \\
\hline 119 & ESES2 & 39.27555 & -0.31528 & 1.13 & -0.51 & 0.967 & 1.02 & 0.69 \\
\hline 120 & ESVda & 42.15218 & 1.4485 & 4.87 & 4.44 & 0.954 & 2.02 & 0.69 \\
\hline 121 & FIHyy & 61.8475 & 24.295 & 3.99 & -3.44 & 0.988 & 2.08 & 0.54 \\
\hline 122 & FRAvi & 43.91608 & 4.878056 & 1.71 & 0.95 & 0.974 & 1.45 & 0.68 \\
\hline 123 & FRFon & 48.47634 & 2.780147 & 1.22 & -0.75 & 0.989 & 0.97 & 0.52 \\
\hline 124 & FRGri & 48.844 & 1.95243 & 3.62 & -3.26 & 0.934 & 1.60 & 0.51 \\
\hline 125 & FRLBr & 44.71711 & -0.7693 & 1.61 & -1.04 & 0.973 & 1.23 & 0.57 \\
\hline 126 & FRMau & 43.38528 & 1.292222 & 2.06 & 1.56 & 0.979 & 1.35 & 0.51 \\
\hline 127 & FRPue & 43.74139 & 3.595833 & 1.62 & 1.19 & 0.990 & 1.11 & 0.66 \\
\hline 128 & FRlus & 46.41557 & 0.119218 & 1.15 & 0.16 & 0.988 & 1.19 & 0.55 \\
\hline 129 & IEDri & 51.98669 & -8.75181 & 1.77 & -1.43 & 0.959 & 1.05 & 0.50 \\
\hline 130 & IEKil & 51.96836 & -9.90031 & 2.09 & -1.78 & 0.949 & 1.11 & 0.50 \\
\hline 131 & ILYat & 31.345 & 35.0515 & 4.21 & 3.67 & 0.989 & 2.08 & 0.78 \\
\hline 132 & ITAmp & 41.9041 & 13.60516 & 1.96 & -0.67 & 0.925 & 1.89 & 0.66 \\
\hline 133 & ITCas & 45.07005 & 8.717523 & 1.08 & 0.19 & 0.983 & 1.07 & 0.56 \\
\hline 134 & ITCol & 41.84936 & 13.58814 & 6.70 & 6.59 & 0.974 & 1.21 & 0.66 \\
\hline 135 & ITLav & 45.9562 & 11.28132 & 1.94 & 1.47 & 0.979 & 1.27 & 0.62 \\
\hline 136 & ITMBo & 46.01468 & 11.04583 & 3.94 & 3.30 & 0.947 & 2.17 & 0.64 \\
\hline 137 & ITNon & 44.69019 & 11.09109 & 6.95 & -6.43 & 0.914 & 2.70 & 0.55 \\
\hline 138 & ITRen & 46.58686 & 11.43369 & 1.98 & 0.24 & 0.969 & 1.97 & 0.63 \\
\hline 139 & ITRo1 & 42.40812 & 11.93001 & 3.70 & 3.45 & 0.995 & 1.38 & 0.70 \\
\hline 140 & ITRo2 & 42.39026 & 11.92093 & 4.65 & 4.11 & 0.990 & 2.30 & 0.70 \\
\hline 141 & ITSRo & 43.72786 & 10.28444 & 2.15 & 1.41 & 0.942 & 1.64 & 0.62 \\
\hline 142 & ITTor & 45.84444 & 7.578055 & 3.02 & 2.70 & 0.978 & 1.38 & 0.66 \\
\hline 143 & NLCa1 & 51.971 & 4.927 & 2.12 & -1.49 & 0.967 & 1.51 & 0.50 \\
\hline 144 & NLHor & 52.24035 & 5.071301 & 2.95 & -1.81 & 0.897 & 2.34 & 0.52 \\
\hline 145 & NLLan & 51.9536 & 4.9029 & 2.13 & -1.42 & 0.950 & 1.66 & 0.50 \\
\hline 146 & NLLoo & 52.16658 & 5.743556 & 2.93 & -2.21 & 0.958 & 1.94 & 0.45 \\
\hline 147 & NLLut & 53.39892 & 6.356028 & 2.02 & -1.36 & 0.953 & 1.54 & 0.52 \\
\hline 148 & PLWet & 52.7622 & 16.3094 & 5.69 & -3.54 & 0.761 & 4.50 & 0.50 \\
\hline 149 & PTMi2 & 38.4765 & -8.02455 & 2.18 & 1.15 & 0.953 & 1.87 & 0.73 \\
\hline 150 & RUChe & 68.61472 & 161.3392 & 2.42 & -1.12 & 0.987 & 2.19 & 0.77 \\
\hline 151 & RUCok & 70.82914 & 147.4943 & 6.28 & -2.71 & 0.878 & 5.76 & 0.72 \\
\hline 152 & RUZot & 60.8008 & 89.3508 & 5.09 & -3.80 & 0.979 & 3.48 & 0.54 \\
\hline 153 & Rufyo & 56.46153 & 32.92208 & 3.70 & -2.15 & 0.959 & 3.05 & 0.47 \\
\hline 154 & SESk2 & 60.12967 & 17.84006 & 3.32 & -3.04 & 0.986 & 1.37 & 0.52 \\
\hline 155 & UKPL3 & 51.45 & -1.26667 & 2.43 & -1.42 & 0.885 & 1.99 & 0.50 \\
\hline 156 & ZAKru & -25.0197 & 31.4969 & 2.26 & 1.54 & 0.906 & 1.73 & 0.59 \\
\hline
\end{tabular}


(a) TMD view time (hour, UTC)

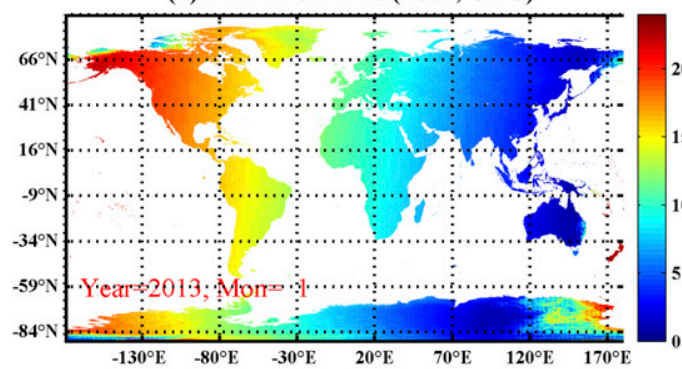

(b) TMN view time (hour, UTC)

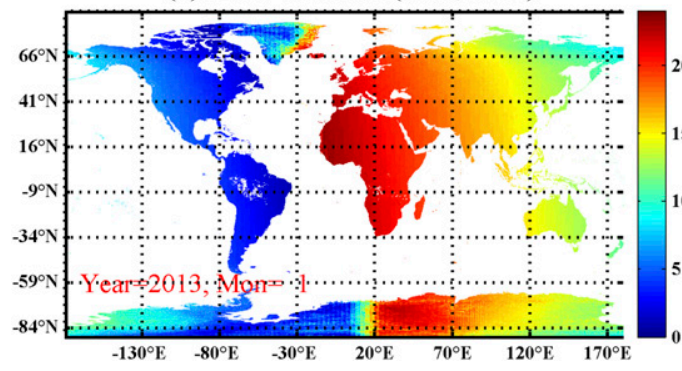

(c) AMD view time (hour, UTC)

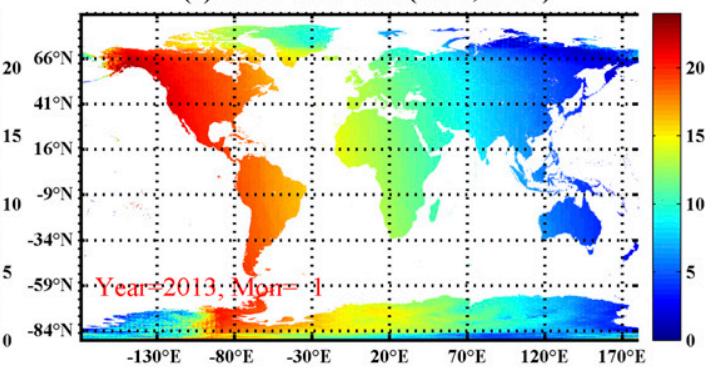

(d) AMN view time (hour, UTC)

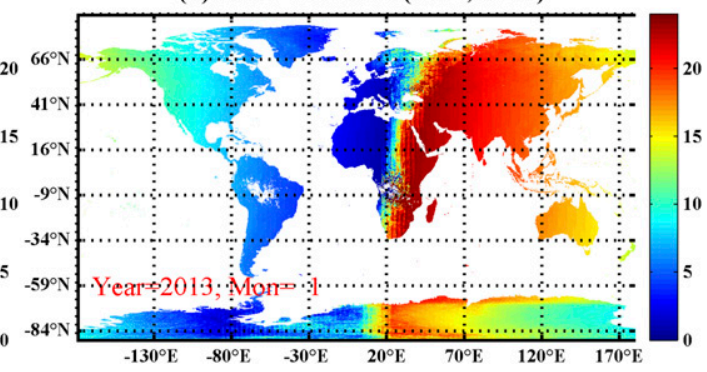

FIG. 1. View time of (a) TMD, (b) TMN, (c) AMD, and (d) AMN LSTs for January 2013.

MODIS monthly LST produced in this work. The grid size of $0.125^{\circ} \times 0.125^{\circ}$ was selected for ERA-Interim LST data downloading. To match the spatial resolution between MODIS and ERA-Interim LST data, the reanalysis data were spatially interpolated to $0.05^{\circ} \times 0.05^{\circ}$, the same grid size as MODIS monthly LST data.

\section{b. MODIS monthly day and night LST}

MODIS LST sensors on board the TerralAqua satellites were launched by NASA in December 1999 and in May 2002 separately. Global LST is measured by both MODIS/Terra and MODIS/Aqua. Multiple LST products have been generated by the MODIS science team since the launch of these platforms. A physics-based day/ night algorithm (Wan and Li 1997) has been used to generate daily LST data (MOD11C1/MYD11C1) at $0.05^{\circ}$ latitude/longitude climate modeling grid. It uses MODIS thermal infrared bands $20(3.660-3.840 \mu \mathrm{m}), 22$ (3.929$3.989 \mu \mathrm{m}), 23(4.020-4.080 \mu \mathrm{m}), 29 \quad(8.400-8.700 \mu \mathrm{m})$, $31 \quad(10.780-11.280 \mu \mathrm{m}), 32(11.770-12.270 \mu \mathrm{m})$, and $33(13.185-13.485 \mu \mathrm{m})$ to correct for atmospheric effects and to retrieve surface emissivity and temperature. Daily LST has both temporal and spatial gaps due to cloud contamination. MOD11C1/MYD11C1 daily LSTs are further processed to MOD11C3/MYD11C3 monthly day and night LST. The MOD11C3/MYD11C3 product comprises the following science dataset layers for daytime and nighttime observations: LSTs; quality-control assessments; observation times; view zenith angles; clearsky coverages; and emissivity for bands 20, 22, 23, 29, 31, and 32 .
When deployed in the Terra and Aqua satellites, the MODIS thermal sensor does not always view ground in a nadir orientation, which means the MODIS LST has a certain dependence on viewing angle. The viewingangle-dependent LST retrieved from the narrow-band MODIS radiance data is different in definition and nature from the ground-based in situ LST estimation from the semispherical longwave radiation measurements carried out at the flux tower sites. This difference makes it difficult to directly assess the directional MODIS LST with ground radiation data. Section $3 \mathrm{~d}$ discusses this problem further in the context of the results obtained when calculating monthly means.

To check the influence of view time and angle on the monthly day and night LST, Figs. 1 and 2 show the sensor view time and view zenith angle included in the MODIS day and night LST products. The result for January 2013 is used simply as a demonstration of what is possible. The temporal variation of the view time during 2003-10 shows that most of the global area has no difference with the view time of January 2013 (see Fig. S1 in the online supplemental material). This could also be checked in Fig. 3. The characters and conclusion derived from Fig. 1 indeed can be taken as a representative of the whole observation time of MODIS sensors.

It is obvious that the synthesized monthly day and night LST product (TMD, TMN, AMD, and AMN) has been built on LST measured at different view angles and view times. However, monthly day and night view times are highly complementary (Fig. 1). The eastern (western) world shows the view time around afternoon 

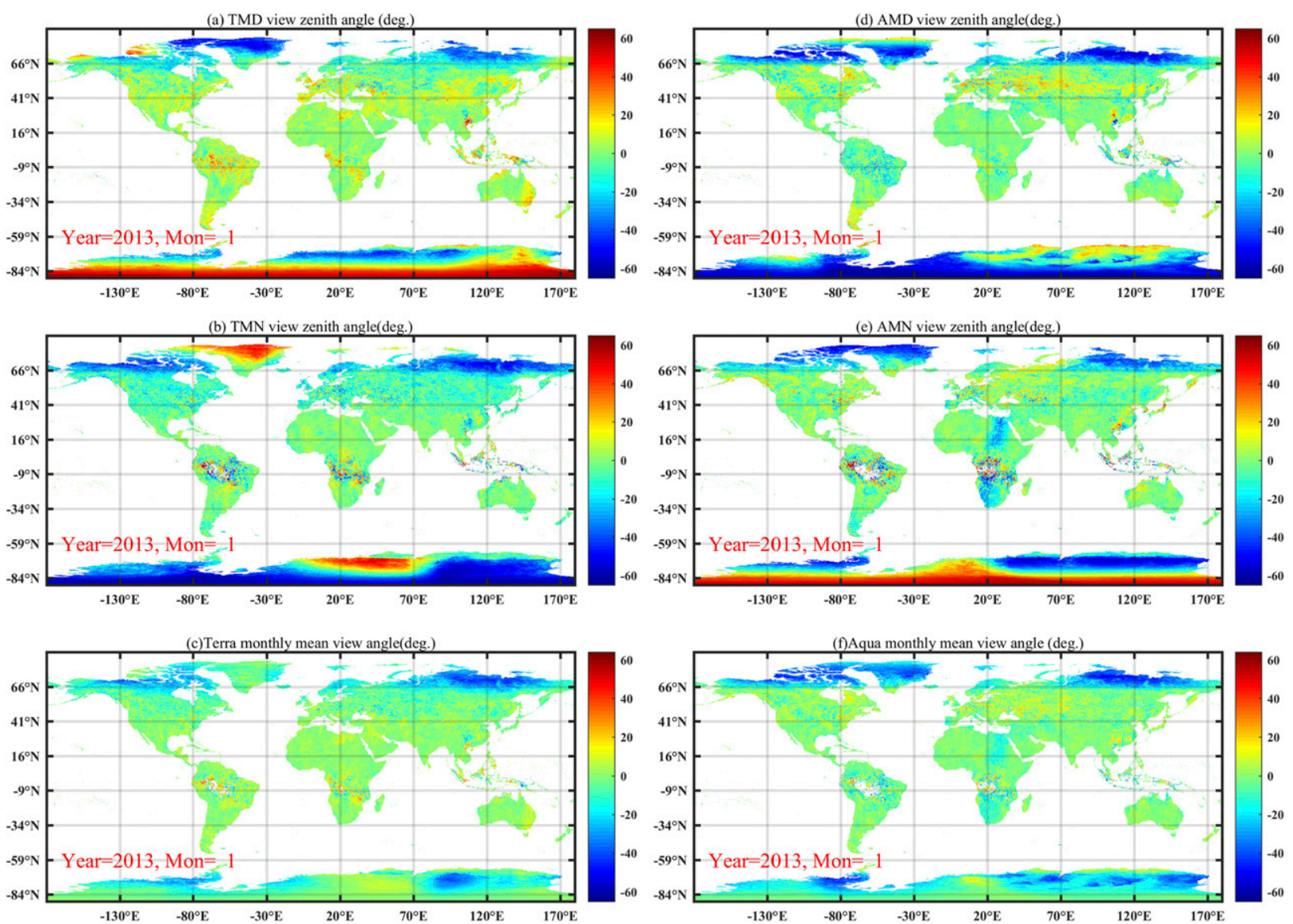

FIG. 2. View zenith angles for January 2013 for (a) TMD, (b) TMN, (c) mean of Terra monthly day and night, (d) AMD, (e) AMN, and (f) mean of Aqua monthly day and night.

(midnight) in TMN (Fig. 1b); meanwhile, it shows midnight (afternoon) view time in TMD (Fig. 1a). The same phenomena is also found in the AMN and AMD LST products (Figs. 1c,d). The highly reliable and complementary nature of the view times makes it reasonable to use the mean of monthly day and night LST across both satellites to represent the monthly mean LST.

The zenith view angle geodistribution demonstrates a significant difference between the polar areas and other regions of the globe (Fig. 2). Most of the global land area between $60^{\circ} \mathrm{N}$ and $60^{\circ} \mathrm{S}$ presents relatively homogenous view angles. The average of the day and night view angle (Figs. 2c,f) has more homogeneity than that of day or night. Averaging of the two sensors' day and night view angles provided the least heterogeneity, and so day and night view times were also averaged separately for Terra and Aqua. Both mean view times have a longitude dependence (Figs. 1c,d). Terra has a high mean view time in the longitude belt between $-30^{\circ}$ and $30^{\circ} \mathrm{E}$, while Aqua has a higher mean view time between $20^{\circ}$ and $70^{\circ} \mathrm{E}$. Other longitude bands have a relatively low mean view time. A longitude dependence is also demonstrated in the mean of the Terra and Aqua view times. Whether the longitude and latitude discrepancies to the mean view times and zenith view angles will emerge in the mean LST products will be examined in section $3 \mathrm{~d}$. The spatial patterns in monthly day and night LST products are closely related to land surface characteristics and are not influenced by limitations caused by the differences in view time and view angle. There is a high degree of spatial consistency between TMD (TMN) and AMD (AMN) LST monthly means, even though their zenith view angles and view times are not consistent geospatially. The biggest variations between TMD and AMD view time and view angle is located in the region around the Antarctic. Despite this, the TMD and AMD monthly LST products do not show significant differences in the Antarctic (Fig. S2). The same holds for TMN and AMN monthly LST. The monthly LST geospatial (Fig. S2) pattern does not shown any abnormal or spatially correlated patterns that can be related to the 
(a) Variation of TMD-view-time(hour)

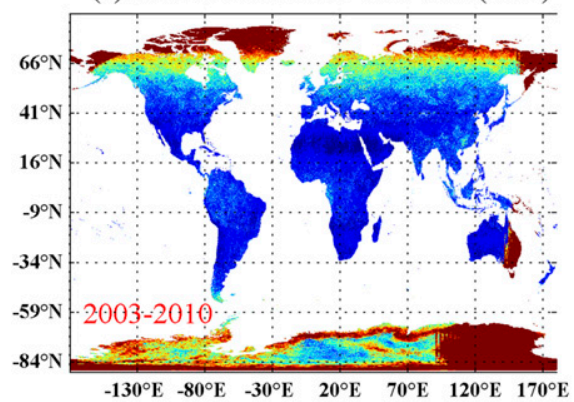

(c) Variation of AMD-view-time(hour)

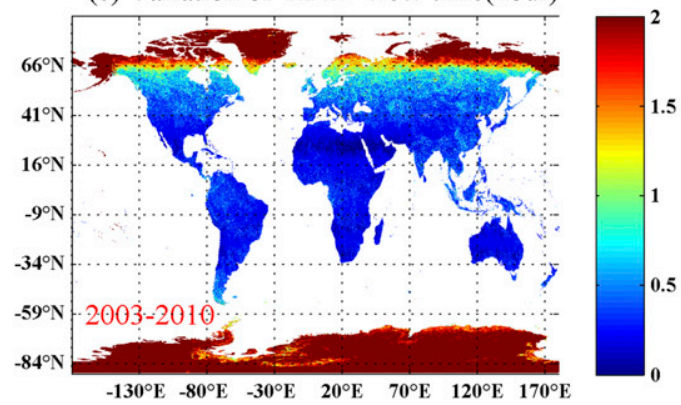

(b) Variation of TMN-view-time(hour)

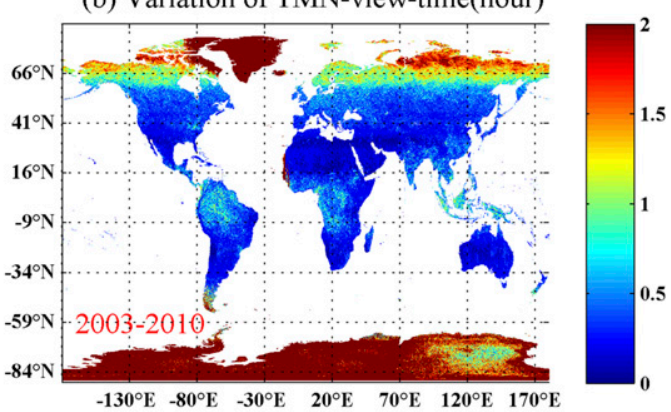

(d) Variation of AMN-view-time(hour)

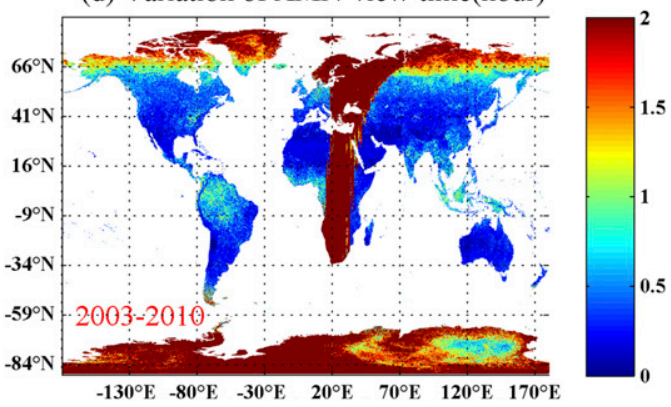

FIG. 3. Variation (maximum minus minimum) of (a) TMD, (b) TMN, (c) AMD, and (d) AMN view time derived from monthly view time during 2003-10.

global view time or view angles illustrated in Figs. 1 and 2. These results indicate that the current monthly day and night LST products have negligible errors due to differences in view time and view angle. Further in situ assessment of the potential errors about errors caused by view time and angle will be carried out in section 3 .

\section{c. Ground measurement data processing}

The ground-measured in situ LSTs were obtained from FluxNet: 23 flux tower stations in China, 17 flux stations in Australia from the Terrestrial Ecosystem Research Network (TERN) OzFlux network, 60 flux stations from AmeriFlux, and 56 flux sites from the European flux network. The station locations are in highly diverse climates and land cover types across four continents. More details are provided in Table 1. About 600 site years of in situ LST during 2003-13 were collected for this study. The land cover types of these sites include bare ground, grassland, alpine grassland, savanna, shrubland, wetland, deciduous broadleaf forest, evergreen broadleaf/needleleaf/coniferous forest, tropical rain forest, mixed forest, urban, and cropland. The station elevation varies from 0 to $5113 \mathrm{~m}$ across the sites. The flux sites in China are from either the ChinaFLUX network (Yu et al. 2006a) or the Tibetan Observation and Research Platform (TORP) sites (Ma et al. 2008). The Australian sites are from TERN OzFlux (http://ozflux.org.au). Others are from AmeriFlux (http://ameriflux.lbl.gov/) and the European Fluxes Database cluster (http://www. europe-fluxdata.eu/home/data/request-data). LST is not directly observed at flux towers. A directly applicable in situ LST may be calculated from observations of the upward and downward longwave radiative fluxes [Eq. (1)]. In the past, longwave radiation ground measurements have been used to validate satellite LST products (Fréville et al. 2014; Holmes et al. 2009; Wang et al. 2008). All flux sites used for the evaluation of LST in this paper were equipped with four-component radiometers (Kipp and Zonen or Hukseflux) mounted at fixed points on the flux towers. These radiometers are calibrated according to the frequency and manner specified by the individual flux networks (Schmidt et al. 2012; Yu et al. 2006b). A four-component radiometer measures both the downward atmospheric longwave radiation and the upward longwave radiation from the surface below. The spectral range of upwelling and downwelling longwave radiation observed by radiometer is from 4.5 to $42 \mu \mathrm{m}$ (Kipp and Zonen) and from 4.5 to $40 \mu \mathrm{m}$ (Hukseflux). The upwelling and downwelling longwave radiation were used to assess in situ LST with a prior knowledge of surface emissivity through Eq. (1), where $L \uparrow$ is upwelling longwave radiation, $L \downarrow$ is downwelling longwave radiation, $\varepsilon_{b}$ is surface broadband emissivity, and $\sigma$ is the Stefan-Boltzmann constant: 

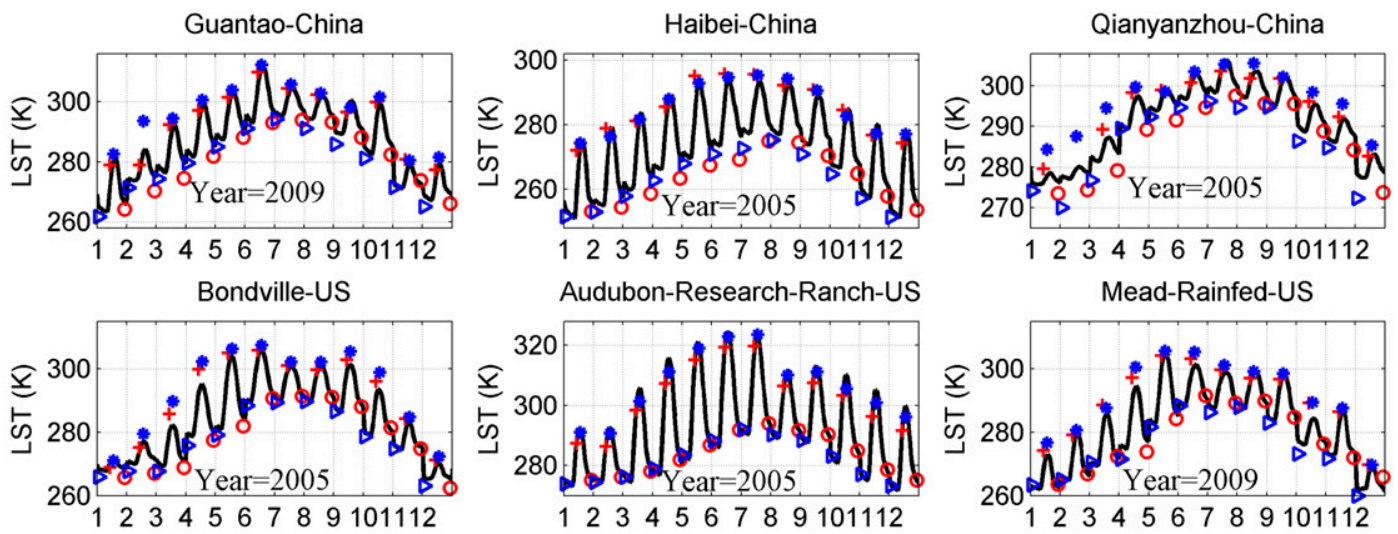

Riggs Creek-Australia
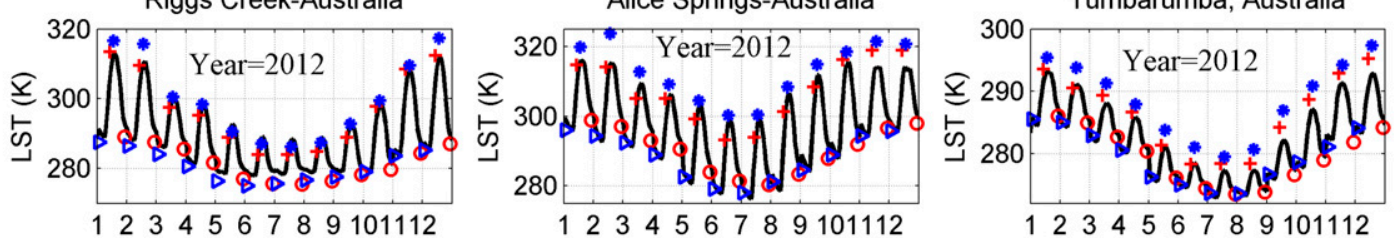

ATNeu-EU
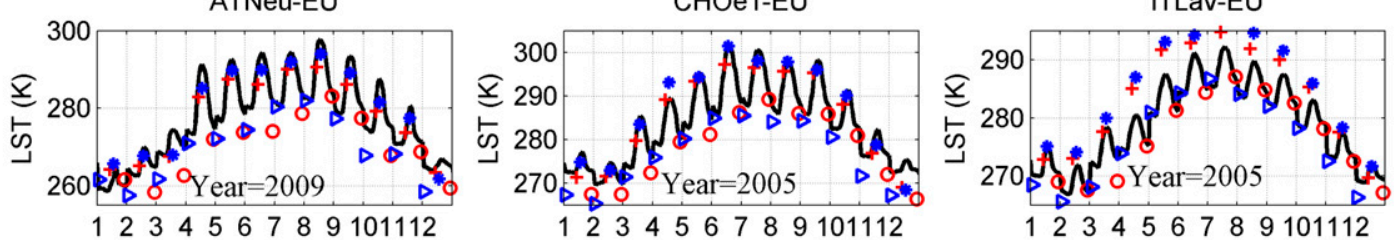

In-situ $\quad \circ$ Terra monthly night LS

+ Terra monthly day LST $\triangleright$ Aqua monthly night LST

- Aqua monthly day LST

FIG. 4. One-year time series of in situ monthly LST measurements: TMN, TMD, AMN, and AMD. The solid line is monthly mean diurnal cycle of in situ LST. The station details are given in Table 1. TMN, TMD, AMN, and AMD LST values were plotted at 2230, 1130, 0230, and $1330 \mathrm{LT}$, respectively.

$$
\mathrm{LST}=\left[\frac{L \uparrow-\left(1-\varepsilon_{b}\right) \times L \downarrow}{\varepsilon_{b} \times \sigma}\right]^{1 / 4},
$$

where $\varepsilon_{b}$ was taken as a linear combination of three thermal infrared narrow band emissivities (band 29, 31, and 32; $\left.\varepsilon_{b}=0.1828 \varepsilon_{29}+0.3867 \varepsilon_{31}+0.4395 \varepsilon_{32}\right)$, which is the approach used in the MOD11C3/MYD11C3 product (Wang et al. 2005). The radiometric measurements at these sites represent 10-30-min averages, and thus the presence of clouds in an averaging period was detected in the time series. The dataset has been quality controlled by the dataset provider and some data have been used in prior publications. AmeriFlux standardized level 2 data (without gap filling; Boden et al. 2013) and OzFlux standardized level 3 data (without gap filling; Beringer et al. 2016) were used in this study. When the ratio of valid in situ LST to the total in situ LST number within each month was lower than $90 \%$, the derived in situ monthly mean LST was not used for the evaluation.

MODIS LST values at the station pixel were selected according to the station's latitude and longitude. The selected MODIS LST values were matched with in situ LSTs. The 10-30-min, in situ LST was preprocessed into averaged 30-min daily means in each month and then monthly mean LST were calculated from these diurnal means. We selected in situ LST values at appropriate time windows in each month to check Terra and Aqua monthly day and night LST. The in situ monthly mean LST was used to verify MODIS monthly mean LST (which is assumed to be the average of MODIS day and night LST) for each sensor from TerralAqua. In total, we used around 6940 pairs of averaged LST readings from the flux tower stations and coincident MODIS LSTs (matchups). A basic site requirement for eddy covariance flux measurements is uniform land cover at the scale of the fetch (typically $1 \mathrm{~km}$ or more). Even though the footprint of tower-mounted radiometers is relatively small [at a height of $10-\mathrm{m}$ sampling around $80 \mathrm{~m}$, according to Schmid (1997)], one would anticipate that, with uniform cover inside the satellite pixel area, the single in situ tower-based radiometric/LST measurement may provide a reasonably representative LST for 
(a)
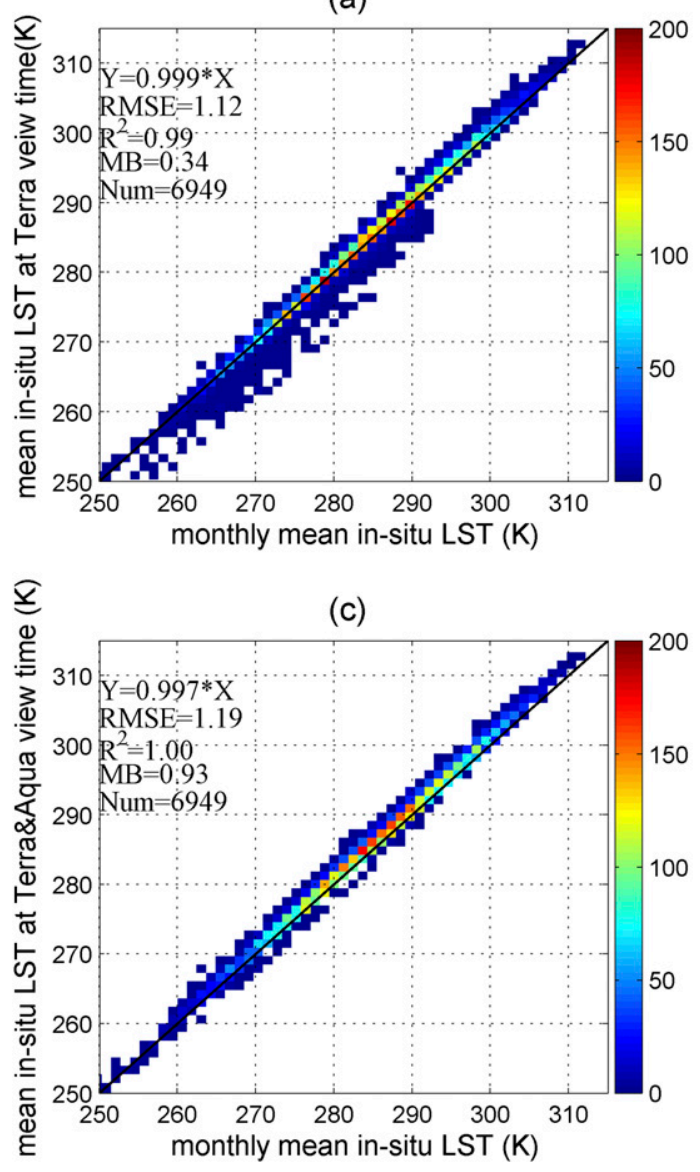

(b)

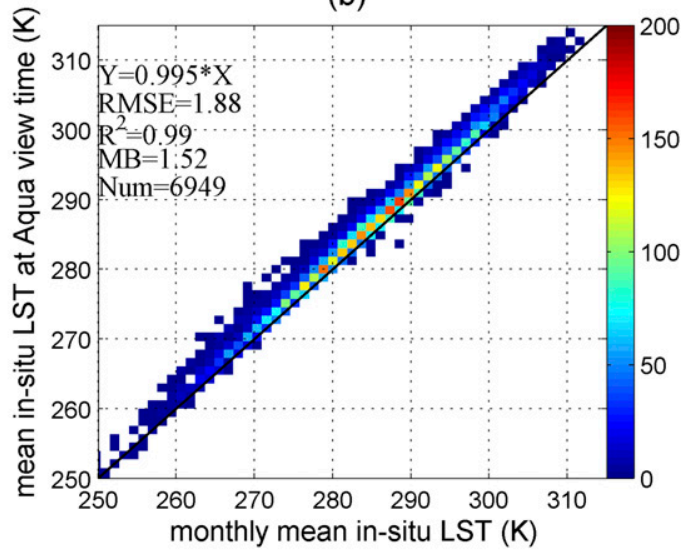

FIG. 5. Scatter density plot for mean in situ LST at (a) 1030 and 2230 LT (Terra view time); (b) 1330 and 0130 LT (Aqua view time); and (c) 1030, 2230, 1330, and 0130 LT (Terra and Aqua view time) against monthly mean in situ LST.

comparison with MODIS LST calculated at the satellite pixel scale. The accuracy of each MODIS monthly LST product was as a result evaluated using mean bias (MB) and root-mean-square error (RMSE) against the monthly in situ LST values.

To make the comparison between in situ and MODIS monthly LST, it was necessary to consider the synchronicity of overpass timing. The Terra MODIS satellite overpass time is 1030 local solar time (descending) and 2230 local solar time (ascending), whereas the Aqua MODIS satellite overpass time is 0130 local solar time (descending) and 1330 local solar time (ascending). Each overpass time for Terra and Aqua is slightly different but is usually within $2 \mathrm{~h}$ of nominal overpass time. The variation of view time during 2003-10 is shown in Fig. 3; 80\%, $73 \%, 66 \%$, and $65 \%$ of pixels in the global coverage of TMD, TMN, AMD, and AMN have a variation smaller than $2 \mathrm{~h}$. As an example, Hu et al. (2014) found that the median local time (LT) of MODIS satellite overpasses for the Houston area are at about 1116 (Terra day), 1334 (Aqua day), 2234 (Terra night), and 0216 local time (Aqua night), calculated from a 10 -yr record. In the monthly diurnal LST time series frame, TMD, AMD, TMN, and AMN values were included at 1030, 1330, 2230, and 0130 local time, respectively (Fig. 4), in the assumption that LST diurnal variation at each site might be consistent with the variation of local solar radiation.

\section{Results}

\section{a. Monthly diurnal variation of LST}

Annual cycles of LST at a selection of 12 flux towers from ChinaFlux, TERN OzFlux, and AmeriFlux are shown in Fig. 4 to illustrate the justification for the possibility of producing monthly mean LST based on monthly day and night LST; the sites chosen were intended to span the maximum range of bioclimatic space. The mean diurnal cycles in each month from the flux stations were within the range of the MODIS monthly night and day LST values, and $90 \%$ of in situ values were within AMN and AMD range. AMD has the highest absolute values in monthly LST among the four MODIS products, followed by TMD. The maximum monthly LST from AMD and TMD show a very good correspondence with the upper bound of 
(a)

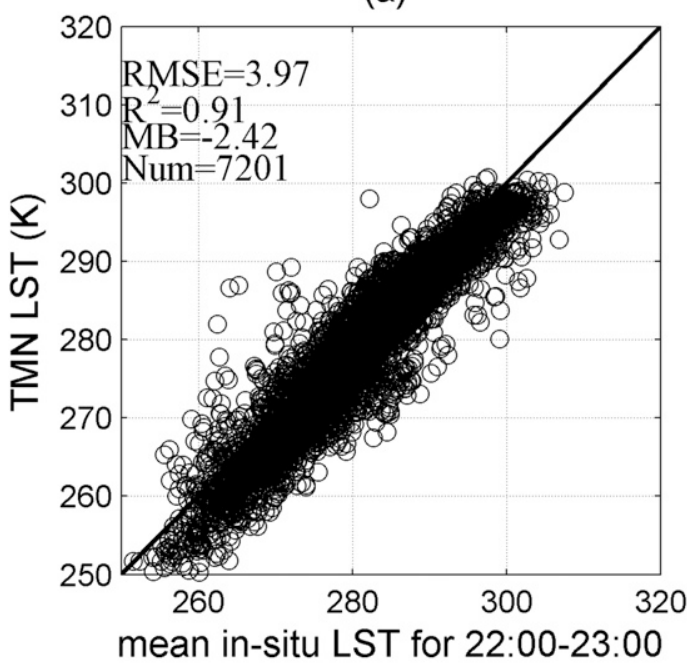

(c)

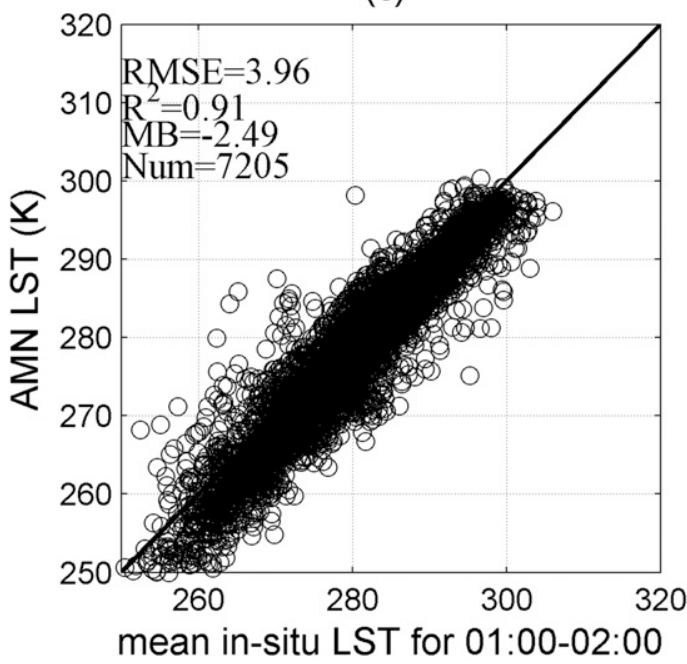

(b)

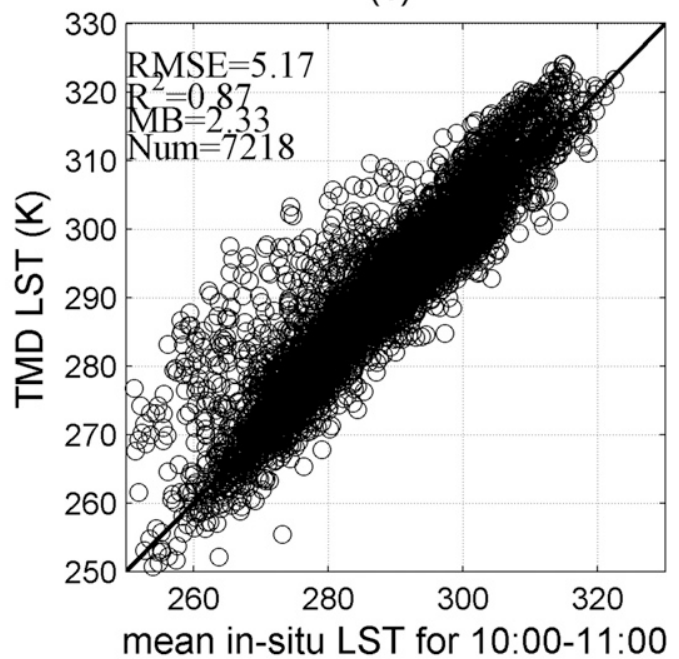

(d)

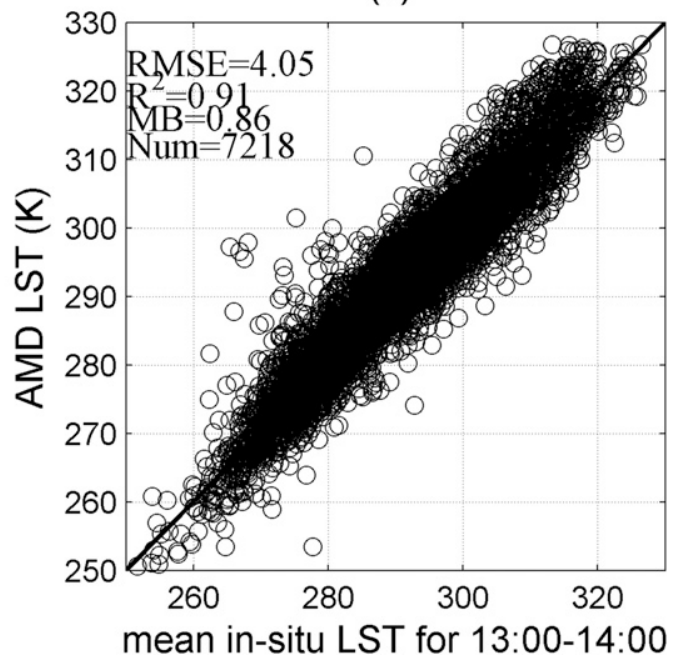

FIG. 6. Scatter points for (a) TMN, (b) TMD, (c) AMN, and (d) AMD against monthly mean in situ LST during 2200-2300, 1000-1100, 0100-0200, and 1300-1400 LT, respectively.

monthly in situ diurnal LST curves. Meanwhile, AMN and TMN follow the seasonal variations reflected by the lower bound of monthly in situ diurnal LST curves. The amplitudes of the in situ observed diurnal cycles were bracketed by the ranges in MODIS night and day LST values at each site for both satellites. The seasonal LST phase shift was represented successfully by MODIS monthly LST. Similar results were found across all the flux sites.

\section{b. Methodology verified at in situ stations}

Comparison between monthly in situ LST and monthly satellite LST was used to test the first assumption of whether LST at the four periods, 1000-1100 LT (TMD view time), 1300-1400 LT (AMD view time), 2200-2300
LT (TMN view time), and 0100-0200 LT (AMN view time), could successfully produce an accurate all-sky monthly mean LST. Figure 5 provides an indication of the success of this approach. The mean value of in situ LST at TMD and TMN view time is plotted against all-sky monthly mean in situ LST in Fig. 5a; the same results for in situ LST at AMD and AMN view time are shown in Fig. 5b. The mean of the four periods against all-sky monthly in situ mean is given by Fig. 5c. It is clear there is a very good correspondence, and most of the points in Fig. 5 are either on or very close to the 1:1 line. There is also a very high coefficient of determination $R^{2}$ in each of these fits. The statistical values (linear fitting slope and $R^{2}$ ) are slightly different among Figs. 5a-c. The MB values are 

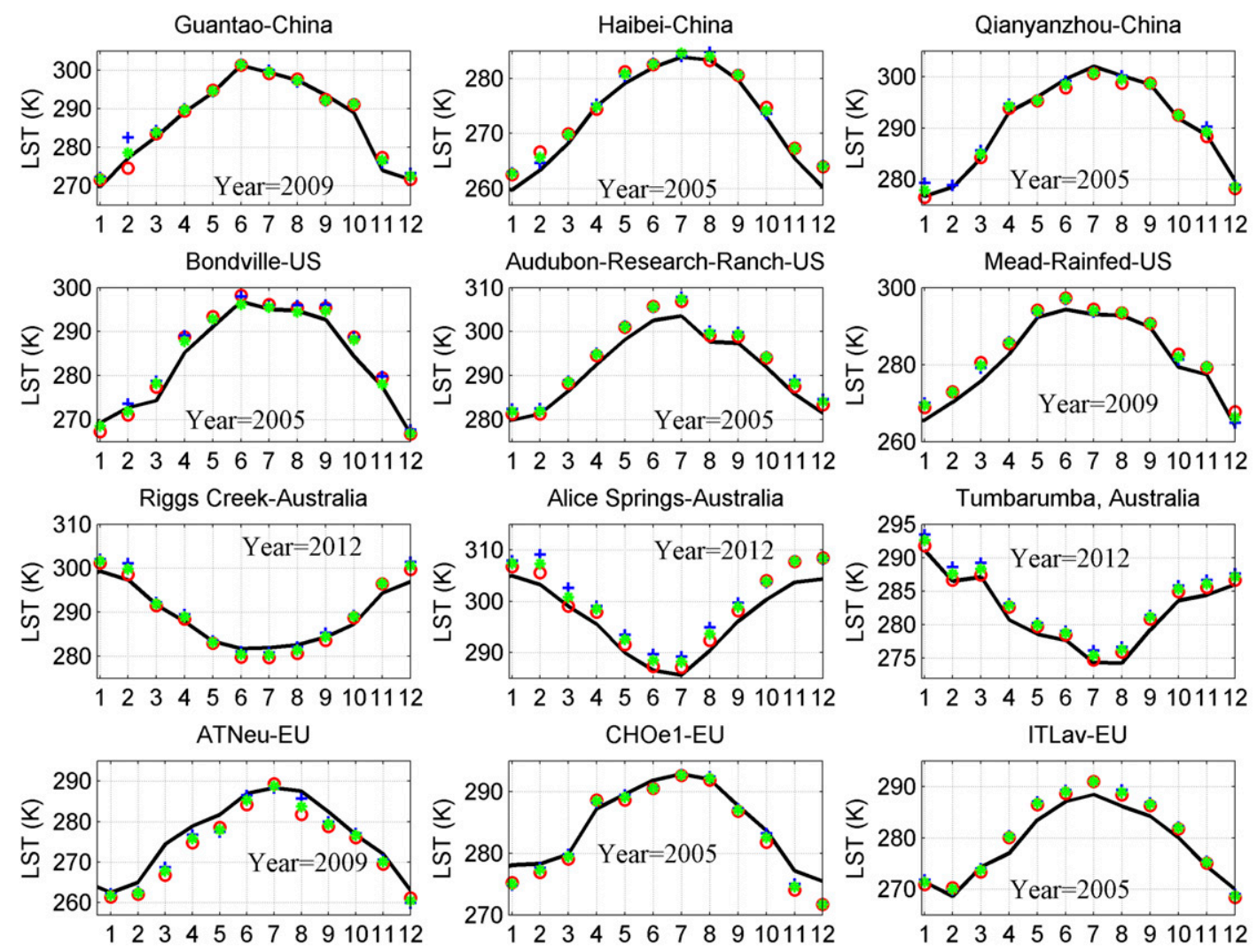

In-situ monthly mean LST $\circ$ mean of Terra Night\&Day $\quad+$ mean of Aqua Night\&Day $\quad$ * mean of Terra Aqua Night\&Day

FIG. 7. One-year time series of in situ monthly mean LST, $\operatorname{LST}_{(\overline{\mathrm{TMD}, \mathrm{TMN}})}, \mathrm{LST}_{(\overline{\mathrm{AMD}, \mathrm{AMN}})}$, and $\operatorname{LST}_{(\overline{\mathrm{AMD}, \mathrm{AMN}, \mathrm{TMD}, \mathrm{TMN})}}$.

$0.34,1.52$, and $0.93 \mathrm{~K}$, which indicates that the calculated mean monthly in situ LST using 1000-1100, 1300-1400, 2200-2300, and 0100-0200 LT view time data will have a $0.93 \mathrm{~K}$ higher bias than the all-sky in situ monthly mean LST. When this positive bias is removed using a calibration offset, it is possible to derive a more accurate monthly LST. These results make it feasible to use any of the mean values of Terra day and night view time in situ LST, the mean of Aqua day and night view time in situ LST, and the mean of Terra and Aqua day/night view time in situ LST to provide an all-sky monthly mean in situ LST that is suitable for subsequent calibration of satellite data.

In the next step, satellite TMD, TMN, AMD, and AMN monthly mean LSTs were analyzed against the corresponding monthly mean in situ LSTs (calculated at satellite view times) to determine if the satellite sensors can successfully represent in situ LST values for the four periods (Fig. 6). As can be seen, the $R^{2}$ is higher than 0.87 and the plot shows that TMD, TMN, AMD, and AMN have a close relationship with monthly mean in situ LST during the four view time periods. The mean bias values were $2.33,-2.42,-2.49$, and $0.86 \mathrm{~K}$ for TMD, TMN, AMN, and AMD, respectively. These four mean bias values can be used to calibrate the four MODIS LST datasets. However, it is preferable not to carry out the calibration before the MODIS day and night LSTs have been processed to monthly means. This is because the day and night satellite LST calibration offsets may usefully cancel each other and as a result reduce the final bias. The purpose of Fig. 6 then is not to demonstrate the overall accuracy of the MODIS monthly day/night LST products, but rather to demonstrate that our assumption that in situ monthly LST could be used to effectively calibrate the monthly satellite LST products does in fact hold.

Considering the reasonable agreement between the in situ measurements and MODIS LST across the four satellite overpasses, the hourly all-sky in situ measurements were processed into monthly mean LST values. The monthly mean in situ LST values were then compared with the mean MODIS values $\operatorname{LST}_{(\overline{\mathrm{AMD}, \mathrm{AMN})} \text {, }}$ $\operatorname{LST}_{(\overline{\mathrm{TMD}, T M N})}$, and LST $(\overline{\mathrm{AMD}, \mathrm{AMN}, \mathrm{TMD}, \mathrm{TMN})})$ Time series comparisons at the 12 flux towers are shown in Fig. 7. The three mean LST values followed variations in monthly mean LST very well, and some step changes were successfully reflected by satellite LST reprocessed using our approach. The different seasonal patterns at 
(a)

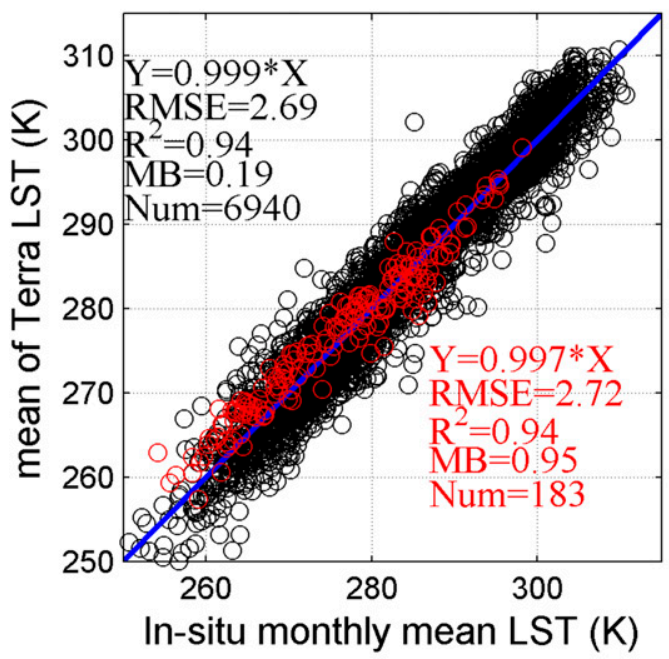

(c)

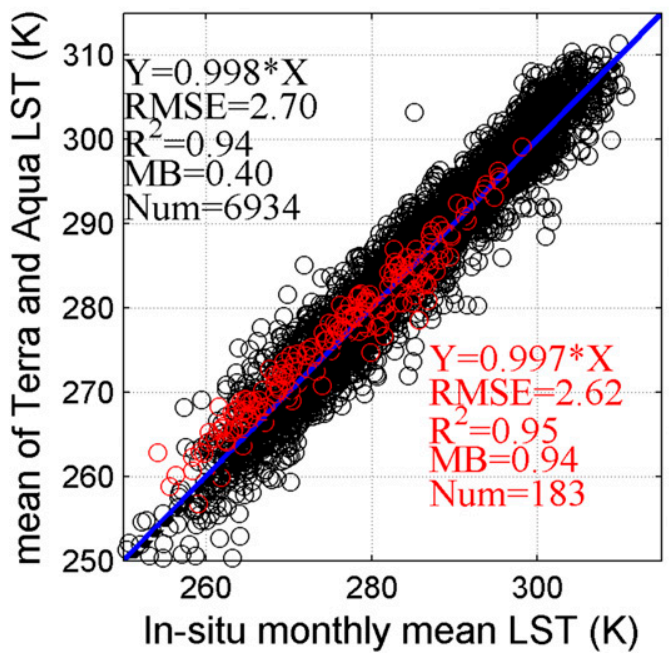

the stations were correctly reflected by the mean values of MODIS clear-sky LST. The mean of Terra night and day LST at Dinghushan (DHS) has an extremely high value for February due to abnormally high TMN and an abnormally low value in June due to unusually low TMN. The points for February at Guantao (GT) and January at Qianyanzhou (QYZ) show that the mean of Terra and Aqua is closer to monthly mean LST than the mean of Terra or mean of Aqua. This is due to both low and high bias that are included in the mean of Terra and Aqua, which produced a relative better monthly mean LST than merely using Terra or Aqua data.

\section{c. Evaluation of the monthly mean all-sky LST}

The correlations across all 156 flux tower stations are plotted in Fig. 8 for a comprehensive performance (b)

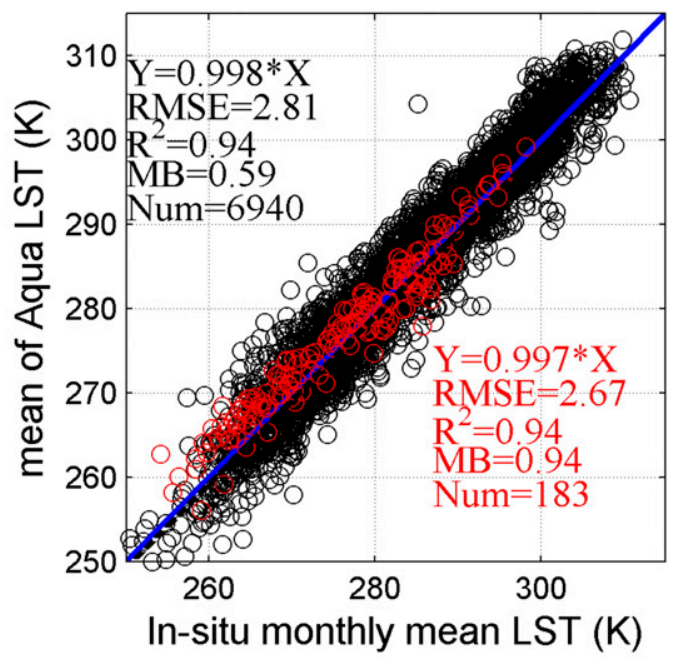

FIG. 8. Scatterplots of (a) $\operatorname{LST}_{(\overline{\mathrm{TMD}, \mathrm{TMN}})}$, (b) $\operatorname{LST}_{(\overline{\mathrm{AMD}, \mathrm{AMN})}}$, and (c) $\operatorname{LST}_{(\overline{\mathrm{AMD}, \mathrm{AMN}, \mathrm{TMD}, \mathrm{TMN})}}$ against in situ monthly mean LST derived with MODIS emissivity. Red circles represent the cold arid and semiarid stations around the Tibetan Plateau (Maqu, Ali, Bijie, SACOL, Gaize, Tanggula, Dangxiong, D105, NPAM, and Haibei). assessment. The three mean bias values $(0.19 \mathrm{~K}$ for Terra, $0.59 \mathrm{~K}$ for Aqua, and $0.40 \mathrm{~K}$ for Terra and Aqua mixed) are positive, which means the monthly mean values from MODIS day and night clear-sky observations are slightly higher than monthly all-sky in situ LST. The mean bias values in Figs. $8 \mathrm{~b}$ and $8 \mathrm{c}$ are lower than that in Figs. 5b and 5c. Cancelation of bias (negative MB in TMN, positive MB in TMD shown in Figs. 6a,b) appears to explain why Terra day and night average $\operatorname{LST}_{(\overline{\mathrm{TMD}, T M N})}$ has a better overall accuracy. This also justifies why we did not perform calibration of the four MODIS LST products before they were averaged. Figure $8 \mathrm{c}$ indicates that the processed mean monthly value $\mathrm{LST}_{(\overline{\mathrm{AMD}, \mathrm{AMN}, \mathrm{TMD}, \mathrm{TMN}})}$ (mean of Terra and $A q u a$ ) yields an acceptable accuracy, with a mean bias of $0.40 \mathrm{~K}$ and average RMSE of $2.70 \mathrm{~K}$. These 


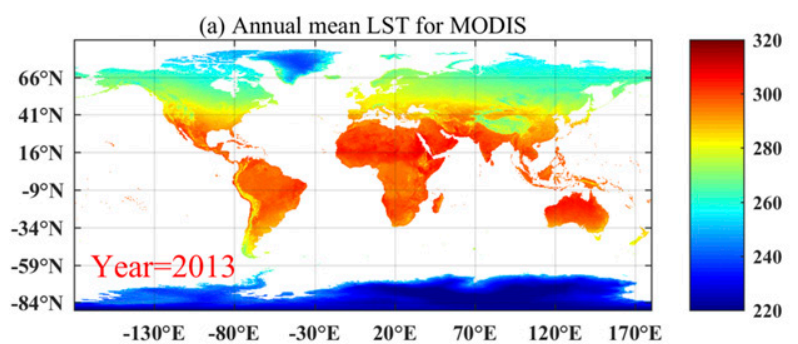

(b) Maximum of monthly LST for MODIS

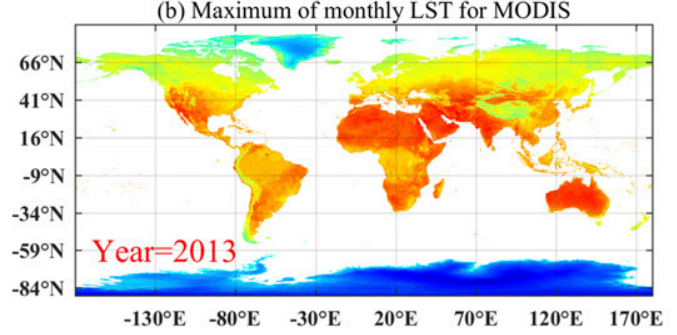

(c) Minimum of monthly LST for MODIS

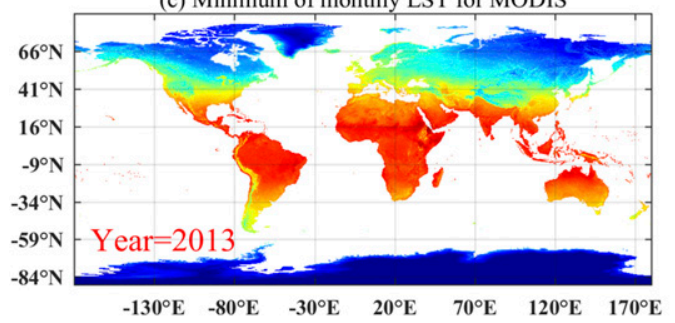

(d) Amplitude of monthly LST for MODIS
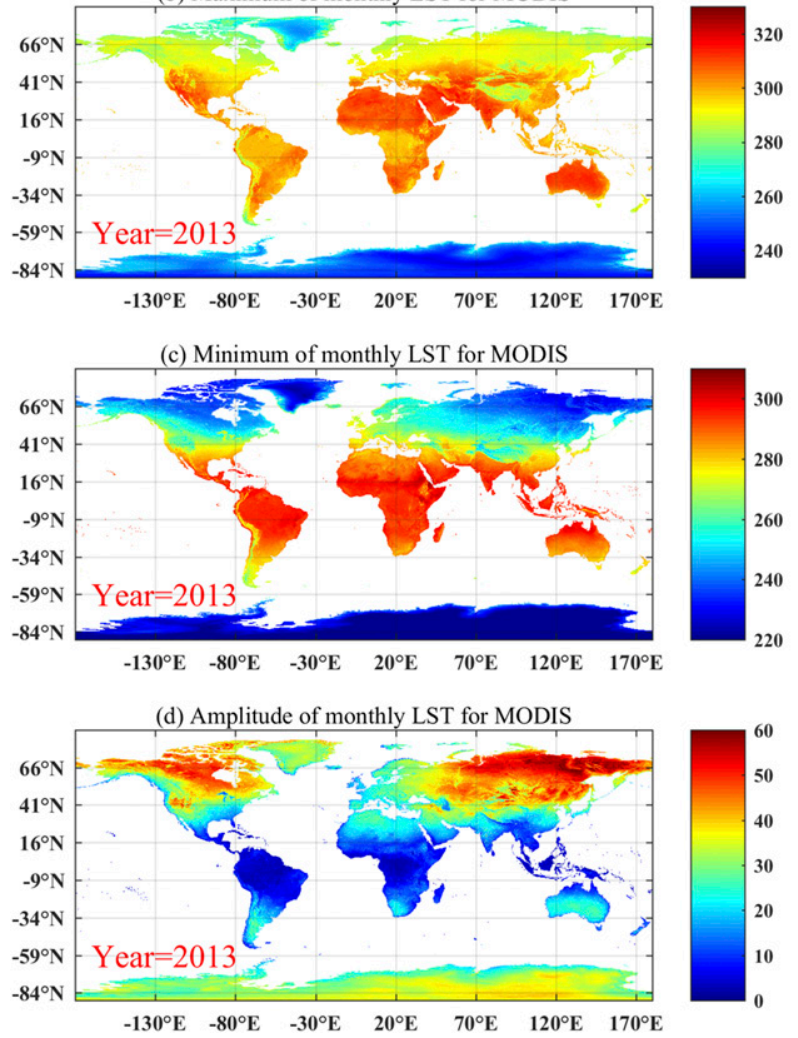

(e) Annual mean LST for ERA-I

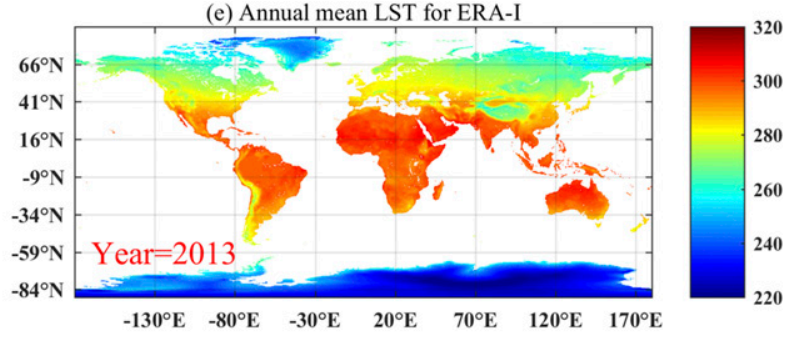

(f) Maximum of monthly LST for ERA-I

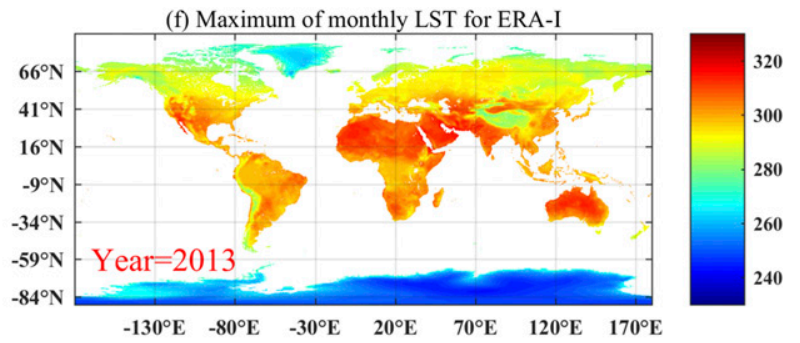

(g) Minimum of monthly LST for ERA-I

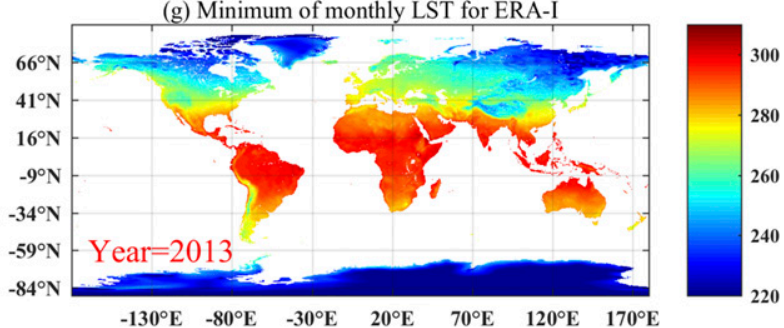

(h) Amplitude of monthly LST for ERA-I

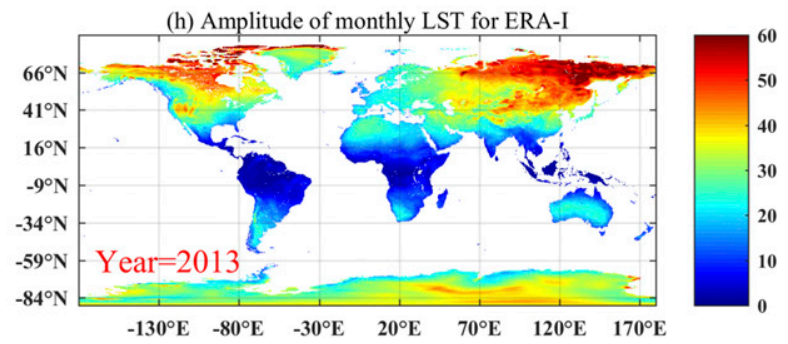

FIG. 9. Geospatial distribution of annual mean LST and maximum, minimum, and amplitude of monthly LST for (left) MODIS and (right) ERA-Interim.

results provide us with a mechanism for generating a reliable global representation of all-sky monthly mean LST with minimal spatial and temporal gaps that is based only on readily available MODIS LST products. Wang and Liang (2009) have suggested that SURFRAD sites are not suitable for $1-\mathrm{km}$-scale comparisons because of the natural heterogeneity of LST. However, the very small number of outliers in Fig. 8 indicates that most of the towers are representative of the MODIS $5-\mathrm{km}$ pixel at a monthly temporal scale.

The in situ evaluation at a limited number of grid points around the globe verified that the monthly mean values were reliable, but this cannot provide any support for the reliability of the satellite LST means over regions where there are a scarcity of ground flux measurements, for example, South America, Africa, and Antarctica. As a result, a comparison with the widely used ERA-Interim reanalysis data was used to check the spatial coverage of the derived monthly mean LST calculated in this study. The annual mean, maximum, minimum, and amplitude of monthly LST derived from MODIS and ERA-Interim were compared (Fig. 9). Both the annual mean LST and maximum/minimum monthly LST calculated from MODIS LST $\overline{(\overline{A M D, A M N, T M D, T M N})}$ have very similar spatial distributions to that of ERA-Interim. The spatial evaluation again confirms that the new MODIS LST processing method developed here will be useful at the global scale. 
(a)

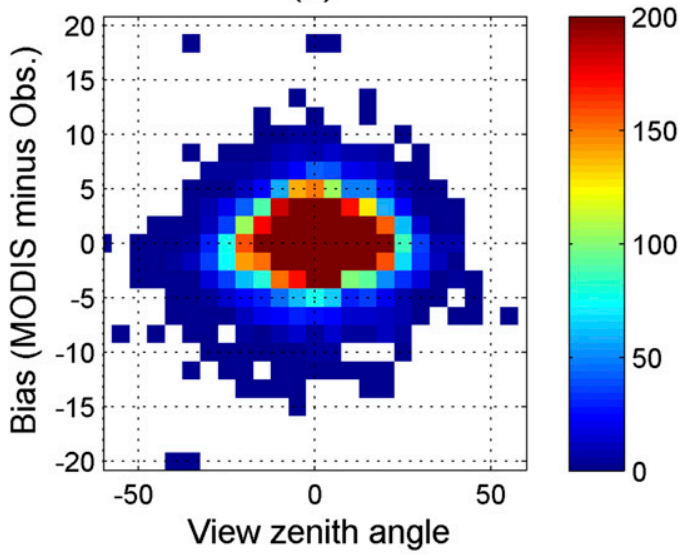

(c)

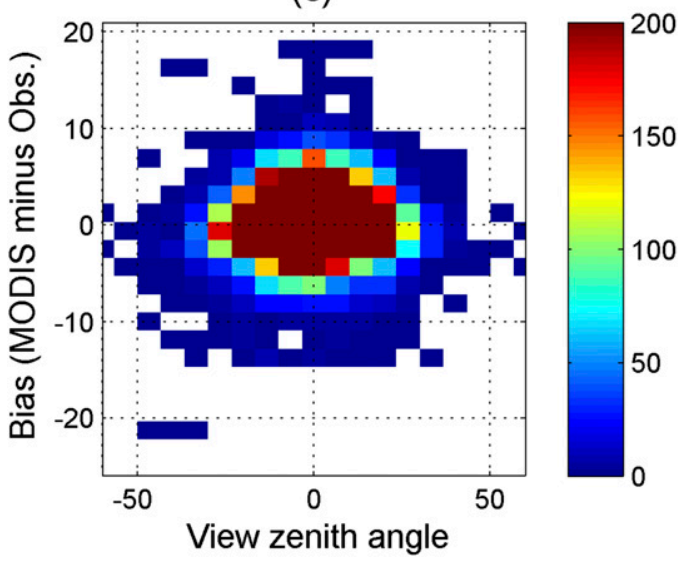

(b)

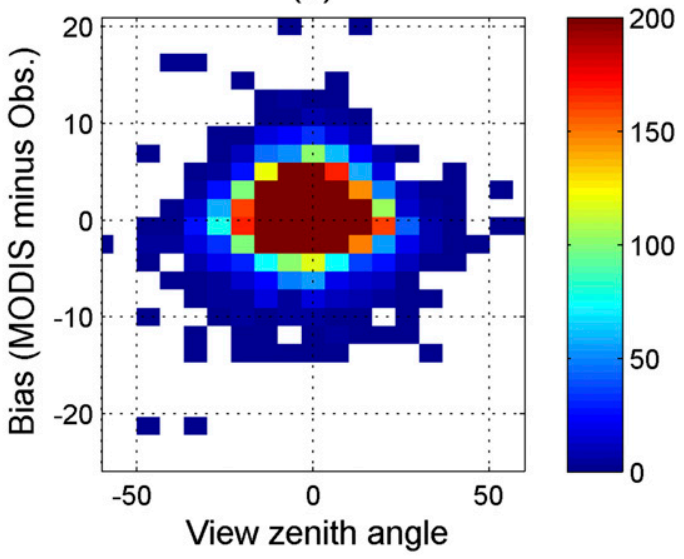

FIG. 10. Scatter density plots for (a) $\operatorname{LST}_{(\overline{T M D}, \mathrm{TMN})}$, (b) $\operatorname{LST}_{(\overline{\mathrm{AMD}, \mathrm{AMN}})}$, and (c) $\operatorname{LST}_{(\overline{\mathrm{AMD}, \mathrm{AMN}, T M D, T M N})}$ against view zenith angle. View zenith angles from TMN and TMD; AMN and AMD; and TMN, TMD, AMN, and AMD were used in (a), (b), and (c), respectively.

\section{d. Possible sources of error in the calculated MODIS monthly LST}

Guillevic et al. (2014) have found LST differences of up to $12 \mathrm{~K}$ between in situ and MODIS data that were attributed to different viewing configurations from MODIS/SEVIRI at sites with large heterogeneity (trees and shading) and at high view angles. MODIS thermal sensor view angles were suggested to be an important factor influencing the results when comparisons were made with in situ data. In our study we have not found any evidence to suggest view angle can influence the accuracy of calculated MODIS monthly LST. Figure 10 shows the relationship between view angles and bias in the derived monthly LST at station pixels. Most of the points are located in the central region encapsulated by view angles from $-20^{\circ}$ to $20^{\circ}$, and in this region there is a bias from -10 to $10 \mathrm{~K}$. Only a small number of points are located in the regions with bias values $>| \pm 10| \mathrm{K}$ and view angles $>| \pm 20|^{\circ}$. In Fig. 10 it can be seen that the scatter density distribution is symmetric both in the dimension of view angle and bias. Our conclusion is that a high view angle does not necessarily show a high bias and a low view angle $\left(<| \pm 20|^{\circ}\right)$ does not necessarily always show a low bias. Once again ERA-Interim reanalysis data were used to evaluate the influence of zenith view angle on MODIS LST. The results are shown in Fig. 11. The LST difference between MODIS and ERA-Interim data plotted against zenith view angle does not show any correlation between them. This means that view angle should not be a significant source for the bias of MODIS all-sky monthly LST at a 5-km pixel size.

The impact of cloud contamination on the accuracy of MODIS monthly LST was also analyzed (Fig. 12). Generally, our analyses show that a high clear-sky ratio (here, clear-sky ratio means the ratio of valid LST in a month) does not mean MODIS LST will have a positive bias, or that a low clear-sky ratio will have a negative bias. Most of the bias values are 
(a)
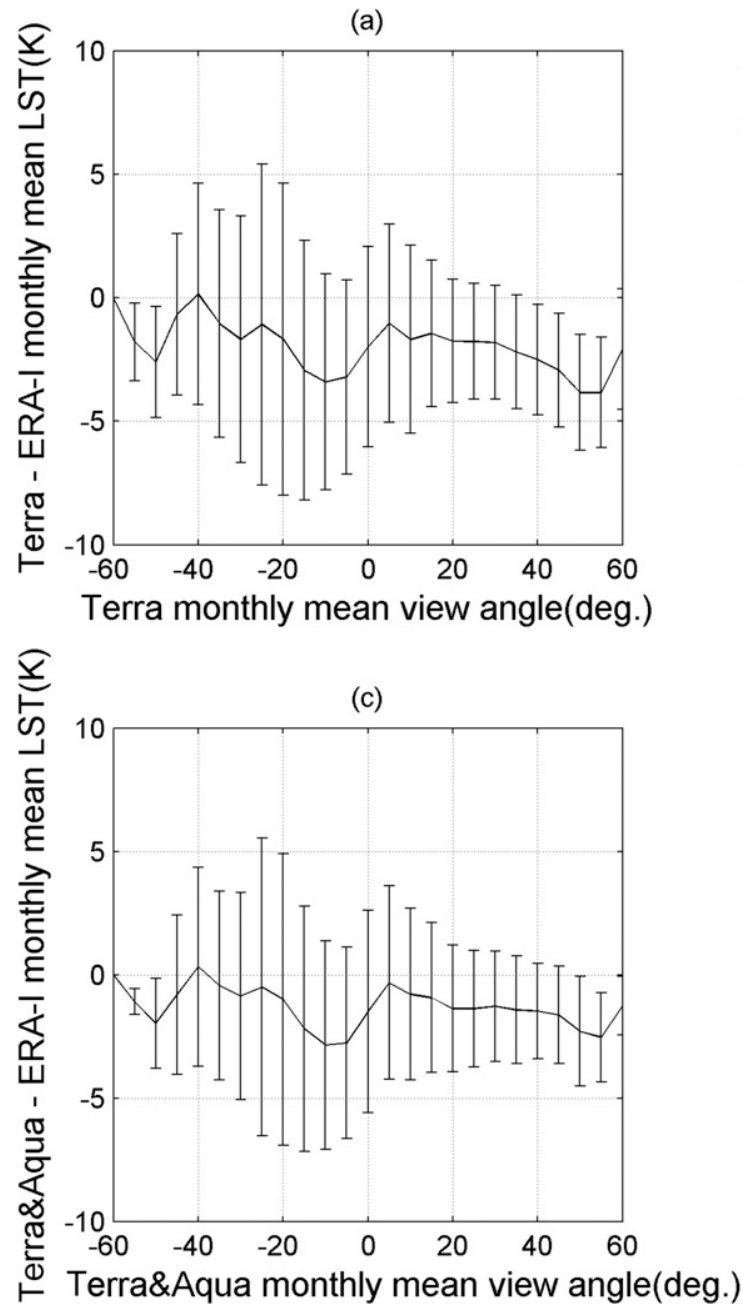

(b)

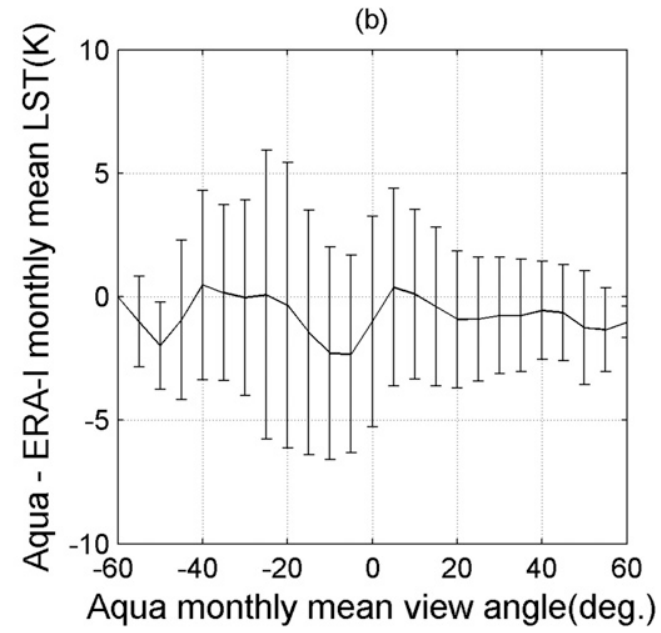

FIG. 11. (a) $\operatorname{LST}_{(\overline{\mathrm{TMD}, \mathrm{TMN}})}$, (b) $\operatorname{LST}_{(\overline{\mathrm{AMD}, \mathrm{AMN}})}$,

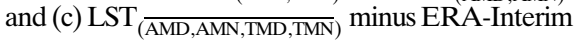
monthly LST against its monthly mean view angle. The error bars show one standard deviation and mean values. symmetric around the $y$ axis $=0$ line. The clear-sky ratio also does not influence the bias distribution. Thus, cloud contamination appears not be an important bias source. The impact of monthly view time on the accuracy of the monthly LST was also investigated (Fig. S3). High or low bias cannot be attributed to a night or day monthly mean view time. Comprehensively, all the error source analysis shows that either the positive or negative bias in the MODIS monthly mean LST cannot be explained by variations in monthly mean view time, view angle, and cloud cover. It has been demonstrated then that by adopting a bias correction to the averages of MODIS day and night LST, a more accurate global monthly LST could be obtained (Fig. 13).

RMSE for different months have been listed in Table 2. It shows that January and December have a bit higher value than other months. The mean RMSE for all months and mean RMSE for snow-free months
(March-October) for $\mathrm{LST}_{(\overline{\mathrm{AMD}, \mathrm{AMN}, \mathrm{TMD}, \mathrm{TMN})}}$ are 2.69 and 2.52 , respectively. The slightly higher RMSE value in winter could be due to the snow cover. Meanwhile, the RMSE for winter does not say that the monthly mean LST has a very high bias for snow cover surface of Antarctica and the Arctic. Actually, the LST assessment for the polar region (see Fig. 9) does show the monthly LST could be used for these areas. Williamson et al. $(2013,2017)$ reported a bias in 1-km daily MODIS LST related to snow cover and cloud contamination. The different conclusions between this paper and theirs can be due to temporal resolution and LST retrieval algorithm. The basic 1-km gridded daily MODIS land surface temperature is produced with a split-window technique that uses MODIS bands 31 and 32. Here we have used 5-km monthly LST products, which are produced with a physics-based day/night algorithm. It uses MODIS thermal infrared bands 20, 22, 23, 29, 31, 32, and 33 to correct atmospheric effects and retrieve day/night 
(a)

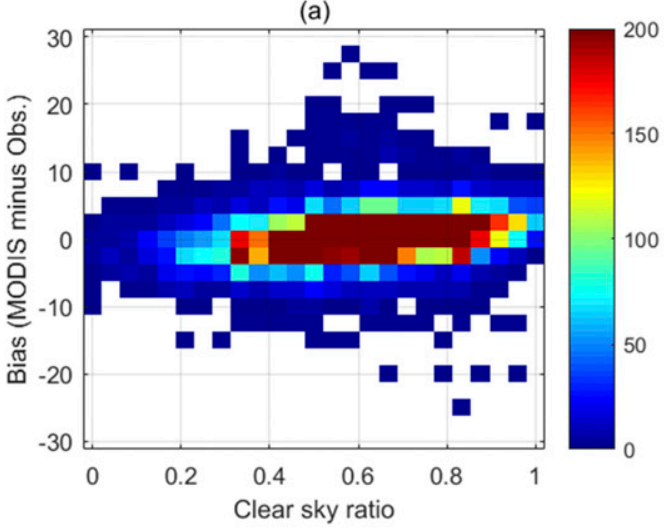

(c)

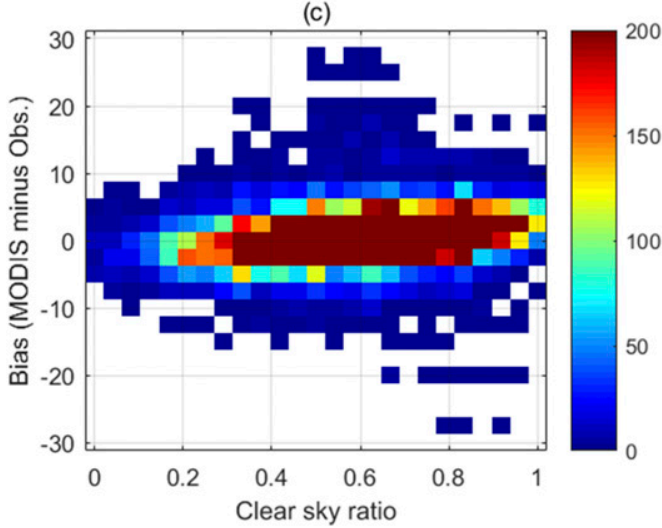

surface emissivity and temperature simultaneously. The different conclusions between ours and Williamson et al.'s can be due to spatial-temporal resolution and LST retrieval algorithm.

\section{Discussion and conclusions}

Previous studies using MODIS nighttime or daytime observations (Qin et al. 2009; Sobrino and Julien 2013; Wang et al. 2008; Zhang et al. 2014) have illustrated the capabilities of individual MODIS monthly day and night LSTs in global climate change analysis, although none of them have made use of the mean of monthly day and night LST (across the Terra and Aqua products). Jiménez-Muñoz et al. (2013) took mean values of Terra monthly day and night LST as a mean monthly LST and found the mean values could detect anomalous LST warming in the drought years in Amazonia, but this is the only published study that we are aware of that has calculated a mean value of monthly LST from MODIS Terra monthly day and night LST data.

In the current study, we have found that the mean of monthly day and night clear-sky LST from both

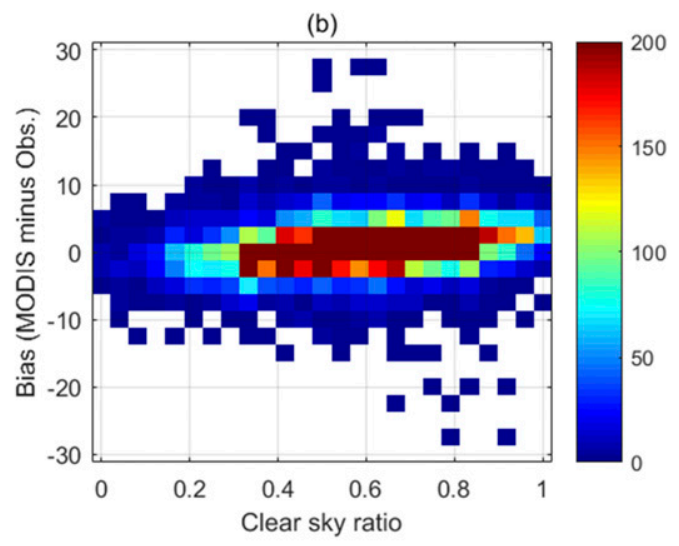

FIG. 12. As in Fig. 10, but against clear-sky ratio.

MODIS satellites best represents the monthly mean LST. As a result, we recommend that future MODIS LST users make use of the mean of MODIS Terra and Aqua monthly night and day LST (MOD11C3 and MYD11C3) $\mathrm{LST}_{(\overline{\mathrm{AMD}, \mathrm{AMN}, \mathrm{TMD}, \mathrm{TMN})}}$ for climate analyses and in validating or improving existing land surface and climate models. Because of the close performance among the three mean values $\left(\mathrm{LST}_{(\overline{\mathrm{TMD}, \mathrm{TMN}})}\right.$, $\operatorname{LST}_{(\overline{\mathrm{AMD}, \mathrm{AMN}})}$, and LST $(\overline{\mathrm{AMD}, \mathrm{AMN}, \mathrm{TMD}, \mathrm{TMN})})$, we would also recommend that whenever either the Aqua or Terra sensors have failed to provide LST information, the other sensor still can be used to composite a continuous monthly LST dataset. Thus, the result of this study has provided modelers and climate scientists with ways to build and use an accurate and largely gap-free MODIS monthly LST dataset.

There are some sources of uncertainty in the LST evaluations against in situ ground measurements. Temperature-based comparisons in clear-sky cases indicate that the accuracy of MODIS LST is better than $1 \mathrm{~K}$ and RMSE is less than $0.7 \mathrm{~K}$ (Coll et al. 2009; Wan 2008). Here we use a conventional method, which 
(a)

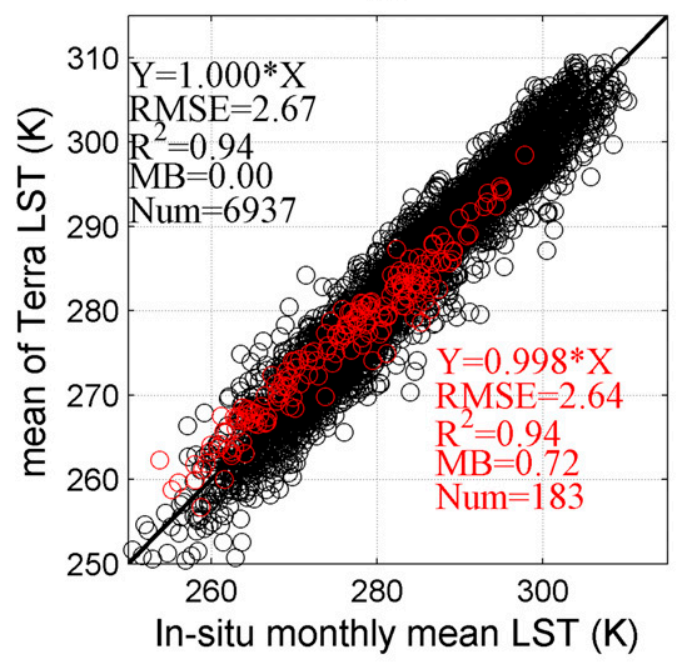

(c)

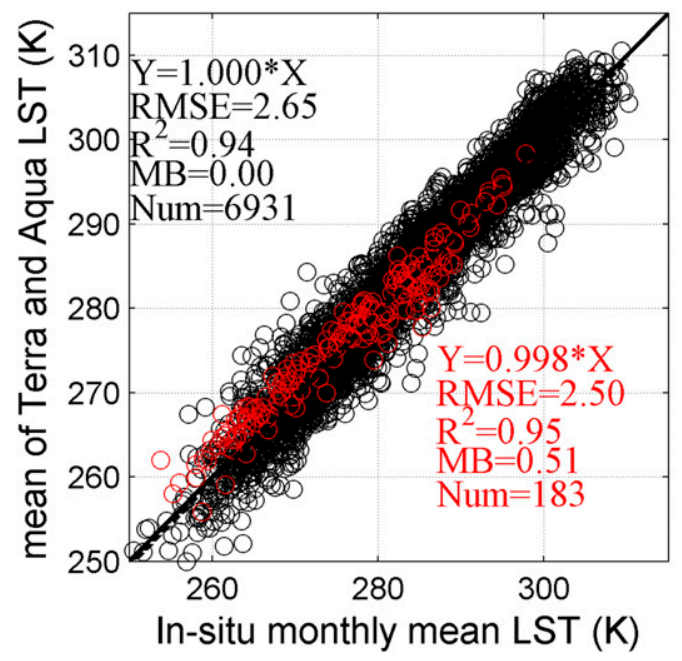

(b)

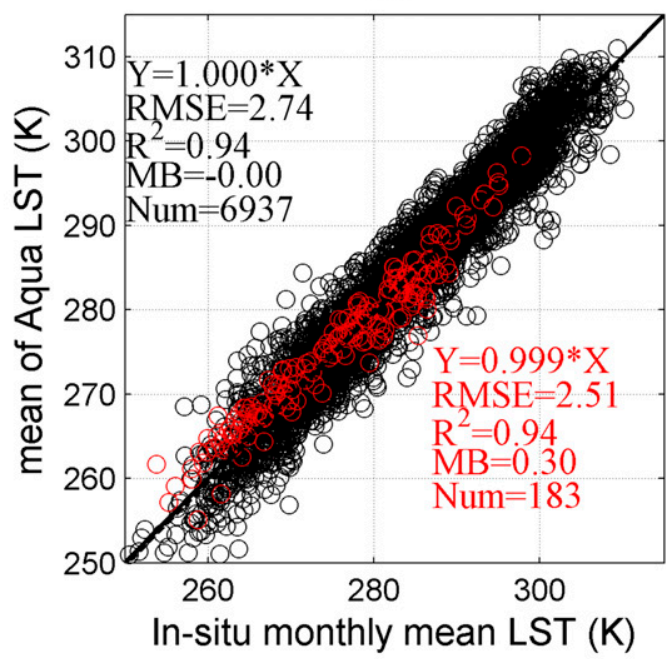

(d)

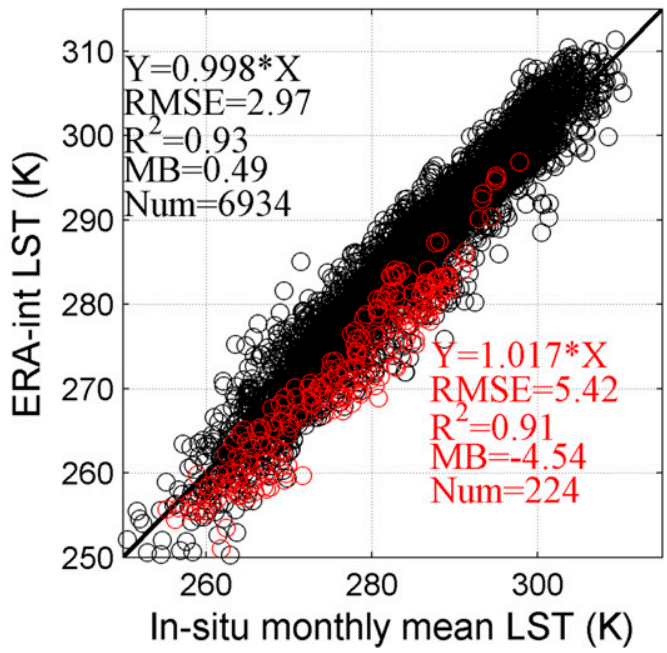

FIG. 13. As in Fig. 8, but for (a) the calibrated $\operatorname{LST}_{(\overline{\mathrm{TMD}, \mathrm{TMN}})}$, (b) the calibrated $\operatorname{LST}_{(\overline{\mathrm{AMD}, \mathrm{AMN}})}$, (c) the calibrated $\operatorname{LST}_{(\overline{\mathrm{AMD}, \mathrm{AMN}, \mathrm{TMD}, \mathrm{TMN})}}$, and (d) ERA-Interim LST against in situ monthly mean LST. shows a higher RMSE of 2.65. Six sites (RUZot, PLWet, ITCol, ITNon, PLWet, and RUCok) out of the 156 sites have a RMSE higher than 5 (Table 1). The evaluation method requires that the LST observed by the ground instruments at the test site is truly representative of the average LST over the $0.05^{\circ} \times 0.05^{\circ}$ pixel, or the site must be located in a thermally homogeneous grid from the point scale to several kilometers. However, some of the sites may not have satisfied this condition. Each pixel of the LST product may contain more than one land type, but MODIS only calculates one skin temperature value for this pixel. It is challenging to interpret this one skin temperature, given different subpixel land types. The six high-RMSE sites are built in developed European land and may have some of the most heterogeneous surfaces. Longwave radiation from in situ radiometers was used to calculate LST at the sites; this process requires that the emissivity is homogeneous in the same area as the satellite pixel. Where there are relatively large RMSE differences between site-level in situ LSTs and satellite LSTs could be explained by additive errors in LST and emissivity due to inhomogeneity. The difference between MODIS LST and pyrgeometer-derived LST can be also caused by the different spectral band used by the two sensors.

The main limitation of satellite infrared measurements of LST is their inability to penetrate clouds, limiting them to clear-sky conditions. One of the important 
TABLE 2. RMSE values derived from in situ LST vs MODIS LST.

\begin{tabular}{llllllllllllll}
\hline & & & & & & & & & & & & & $\begin{array}{c}\text { Mean RMSE for } \\
\text { Jan } \\
\text { all months/mean RMSE for } \\
\text { snow-free (Mar-Oct) months }\end{array}$ \\
\hline $\begin{array}{c}\text { Terra } \\
\text { monthly LST }\end{array}$ & 3.22 & 2.96 & 2.56 & 2.66 & 2.63 & 2.45 & 2.44 & 2.40 & 2.45 & 2.46 & 2.93 & 3.08 & $2.69 / 2.50$ \\
$\begin{array}{c}\text { Aqua } \\
\text { monthly LST }\end{array}$ & 3.33 & 3.20 & 2.83 & 2.78 & 2.65 & 2.45 & 2.61 & 2.54 & 2.58 & 2.61 & 2.95 & 3.61 & $2.85 / 2.63$ \\
$\begin{array}{c}\text { Terra } \text { and Aqua } \\
\text { monthly LST }\end{array}$ & 3.20 & 2.98 & 2.63 & 2.67 & 2.59 & 2.40 & 2.47 & 2.43 & 2.48 & 2.49 & 2.90 & 3.06 & $2.69 / 2.52$ \\
\hline
\end{tabular}

requirements of successful LST retrieval from satellites is the effective removal of cloud contamination. Statistical interpolation could provide an estimate of the skin temperature for cloudy scenes. To estimate surface skin temperatures from infrared measurements in cloudy conditions, Jin and Dickinson (1999) and Jin (2000) proposed a technique that uses both neighboring (in time or space) clear pixels and the surface energy balance. A seamless and gap-free daily LST at continental scale can be reconstructed using temporal Fourier analysis transforms (Scharlemann et al. 2008), statistical modeling (Metz et al. 2014), and spatial and temporal interpolation/aggregation (Crosson et al. 2012; Metz et al. 2014). However, a global, gap-free, all-sky monthly mean LST has not yet been built. When the MODIS science team resampled the MODIS daily $1 \mathrm{~km}$ LST to monthly $5 \mathrm{~km}$, both spatial and temporal gaps were largely overcome. Here, we have shown that when the MODIS LST was further reprocessed into monthly mean LST, the cloud effects on the monthly mean LST diminish and there are essentially no spatial and temporal gaps in the 5-km monthly LST (MOD11C3 and MYD11C3) dataset.

Although the relatively short duration of the MODIS LST time series (until present around 15 years) is not ideal for climate change analysis, previous studies have shown MODIS LST has already had successful applications in climate warming trend analysis (Jin and Terrence 2012; Zhang et al. 2014) and drought monitoring (Jiménez-Muñoz et al. 2013). With the growing extension of the data collection, more interesting results will no doubt be discovered in the future by using an accurate monthly mean based on long time series LST data from MODIS. As an independent 15-yr global consistent LST observation, the produced monthly LST could be used in a large variety of applications: 1) to diagnose the problems in numerical weather prediction land-air interaction transfer coefficients, especially over hilly areas; 2) to initialize the upper boundary for soil temperature and soil moisture simulations in land surface physical process models; and 3) as an input in satellite-derived global land surface energy balance and evapotranspiration calculation. The results for the 10 stations (Maqu, Ali, Bijie, SACOL, Gaize, Tanggula, Dangxiong, D105, NPAM, and Haibei) around the Tibetan Plateau in Fig. 13 demonstrate that MODIS monthly LST has a much better accuracy than ERAInterim. ERA-Interim has a relative large cool bias (with $\mathrm{MB}=-4.54$ ) in its LST modeling, consistent with the wet bias in its soil moisture simulation. The cool LST and wet soil moisture bias in the land surface physics model does reflect a consistent problem in current process modeling for this region.

In this study, we have built the monthly LST dataset from polar-orbiting satellites (MODIS Terra and Aqua). When LST observed by the geostationary sensors are combined and fused with the monthly LST from polar satellites, the potential advantages of both polar-orbiting and geostationary sensors will have been realized; this is a direction we are currently working on.

Acknowledgments. We thank the MODIS projects for providing the data used in this paper. Xuelong Chen is funded by the Faculty of Geo-Information Science and Earth Observation, University of Twente. Dr. Zhengming Wan from the MODIS science team and Dr. Isabel Trigo (IPMA) are thanked for comments on a draft of this manuscript. We also wish to thank the anonymous reviewers for their constructive comments. We acknowledge the following AmeriFlux sites for their data records: Us-Ar1, US-Ar2, US-Arm, US-An1, US-An2, US-An3, US-Aud, US-Blk, US-Blo, US-Bo1, US-Bo2, US-Br1, US-CaV, US-ChR, US-Cop, US-Ctn, US-Dk1, US-Dk2, US-Dk3 US-EML, US-Fmf, US-Fuf, US-FwF, US-FPe, US-FR1, US-GLE, US-GOO, US-Ho1, US-Ho2, Us-Ho3, US-Ivo, US-KFS, US-Mpj, US-MRf, US-Ne1, US-Ne2, Us-Ne3, Us-Me2, US-Me3, Us-Me6, US-MOz, US-MMS, US-NR1, US-NC1, US-NC2, US-SRC, US-SRM, US-Seg, US-Ses, US-Slt, US-SFP, 
US-UMB， US-Var， US-Vcm，US-Vcp，US-WBW, US-Whs, US-WCr, US-Wrc, US-Wkg, US-Wjs, BR-Sa1, and BR-Sa3 and the Wind River datasets. In addition, funding for AmeriFlux data resources was provided by the U.S. Department of Energy's Office of Science. The following TERN OzFlux sites are acknowledged for providing data: Adelaide River, Alice Springs, Arcturus, Calperum, Cape Tribulation, Cumberland Plains, Cow Bay, Daly Pasture, Daly Regrowth, Daly Uncleared, Dry River, Fogg Dam, Gingin, Great Western Woodlands, Howard Springs, Otway, Red Dirt Melon, Riggs Creek, Robson Creek, Sturt Plains, Ti Tree East, Tumbarumba, Wallaby Creek, Warra, and Whroo. Support for data collection and archiving of TERN OzFlux data was provided through the Australia Terrestrial Ecosystem Research Network (TERN; http:// www.tern.org.au) and the Australian Research Council. We acknowledge Xiangde Xu (CMA), Lide Tian (ITP, CAS), Yu Zhang (CAREERI, CAS), Bin Zhao (Fudan University), Dawen Yang (Tsinghua University), Guirui Yu (IGSNRR/CAS), Jianping Huang (Lanzhou University), and Shaomin Liu (Beijing Normal University) for providing us with their flux tower data sets from ChinaFlux and TORP.

\section{REFERENCES}

Baldocchi, D., and Coauthors, 2001: FLUXNET: A new tool to study the temporal and spatial variability of ecosystemscale carbon dioxide, water vapor, and energy flux densities. Bull. Amer. Meteor. Soc., 82, 2415-2434, doi:10.1175/ 1520-0477(2001)082<2415:FANTTS > 2.3.CO;2.

Beringer, J., and Coauthors, 2016: An introduction to the Australian and New Zealand flux tower network - OzFlux. Biogeosciences, 13, 5895-5916, doi:10.5194/bg-13-5895-2016.

Boden, T. A., M. Krassovski, and B. Yang, 2013: The AmeriFlux data activity and data system: An evolving collection of data management techniques, tools, products and services. Geosci. Instrum. Methods Data Syst., 2, 165-176, doi:10.5194/ gi-2-165-2013.

Coll, C., Z. Wan, and J. M. Galve, 2009: Temperature-based and radiance-based validations of the V5 MODIS land surface temperature product. J. Geophys. Res., 114, D20102, doi:10.1029/2009JD012038.

Crosson, W. L., M. Z. Al-Hamdan, S. N. J. Hemmings, and G. M. Wade, 2012: A daily merged MODIS Aqua-Terra land surface temperature data set for the conterminous United States. Remote Sens. Environ., 119, 315-324, doi:10.1016/ j.rse.2011.12.019.

Dee, D. P., and Coauthors, 2011: The ERA-Interim reanalysis: Configuration and performance of the data assimilation system. Quart. J. Roy. Meteor. Soc., 137, 553-597, doi:10.1002/qj.828.

Freitas, S. C., I. F. Trigo, J. Macedo, C. Barroso, R. Silva, and R. Perdigão, 2013: Land surface temperature from multiple geostationary satellites. Int. J. Remote Sens., 34, 3051-3068, doi:10.1080/01431161.2012.716925.

Fréville, H., E. Brun, G. Picard, N. Tatarinova, L. Arnaud, C. Lanconelli, C. Reijmer, and M. van den Broeke, 2014:
Using MODIS land surface temperatures and the Crocus snow model to understand the warm bias of ERA-Interim reanalyses at the surface in Antarctica. Cryosphere, 8, 1361-1373, doi:10.5194/tc-8-1361-2014.

Guillevic, P. C., and Coauthors, 2014: Validation of land surface temperature products derived from the Visible Infrared Imaging Radiometer Suite (VIIRS) using ground-based and heritage satellite measurements. Remote Sens. Environ., 154, 19-37, doi:10.1016/j.rse.2014.08.013.

Holmes, T. R. H., R. A. M. De Jeu, M. Owe, and A. J. Dolman, 2009: Land surface temperature from $\mathrm{Ka}$ band $(37 \mathrm{GHz})$ passive microwave observations. J. Geophys. Res., 114, D04113, doi:10.1029/2008JD010257.

Hu, L., N. A. Brunsell, A. J. Monaghan, M. Barlage, and O. V. Wilhelmi, 2014: How can we use MODIS land surface temperature to validate long-term urban model simulations? J. Geophys. Res. Atmos., 141, 3185-3201, doi:10.1002/2013JD021101.

Imhoff, M. L., P. Zhang, R. E. Wolfe, and L. Bounoua, 2010: Remote sensing of the urban heat island effect across biomes in the continental USA. Remote Sens. Environ., 114, 504-513, doi:10.1016/j.rse.2009.10.008

Inamdar, A. K., and A. French, 2009: Disaggregation of GOES land surface temperatures using surface emissivity. Geophys. Res. Lett., 36, L02408, doi:10.1029/2008GL036544.

Jiménez-Muñoz, J. C., J. A. Sobrino, C. Mattar, and Y. Malhi, 2013: Spatial and temporal patterns of the recent warming of the Amazon forest. J. Geophys. Res. Atmos., 118, 5204-5215, doi:10.1002/jgrd.50456.

Jin, M., 2000: Interpolation of surface radiative temperature measured from polar orbiting satellites to a diurnal cycle: 2. Cloudy-pixel treatment. J. Geophys. Res., 105, 4061-4076, doi:10.1029/1999JD901088.

_ , and R. E. Dickinson, 1999: Interpolation of surface radiative temperature measured from polar orbiting satellites to a diurnal cycle: 1. Without clouds. J. Geophys. Res., 104, 2105-2116, doi:10.1029/1998JD200005.

__ , and E. D. Robert, 2010: Land surface skin temperature climatology: Benefitting from the strengths of satellite observations. Environ. Res. Lett., 5, 044004, doi:10.1088/ 1748-9326/5/4/044004.

_ , and J. M. Terrence, 2012: Land-biosphere-atmosphere interactions over the Tibetan plateau from MODIS observations. Environ. Res. Lett., 7, 014003, doi:10.1088/1748-9326/7/ 1/014003.

Koch, J., A. Siemann, S. Stisen, and J. Sheffield, 2016: Spatial validation of large-scale land surface models against monthly land surface temperature patterns using innovative performance metrics. J. Geophys. Res. Atmos., 121, 5430-5452, doi:10.1002/2015JD024482.

Li, Z., B. Tang, H. Wu, H. Ren, G. Yan, Z. Wan, I. F. Trigo, and J. A. Sobrino, 2013: Satellite-derived land surface temperature: Current status and perspectives. Remote Sens. Environ., 131, 14-37, doi:10.1016/j.rse.2012.12.008.

Ma, Y., S. Kang, L. Zhu, B. Xu, L. Tian, and T. Yao, 2008: Tibetan Observation and Research Platform- Atmosphere-land interaction over a heterogeneous landscape. Bull. Amer. Meteor. Soc., 89, 1487-1492, doi:10.1175/2008BAMS2545.1.

Metz, M., D. Rocchini, and M. Neteler, 2014: Surface temperatures at the continental scale: Tracking changes with remote sensing at unprecedented detail. Remote Sens., 6, 3822, doi:10.3390/ rs6053822.

Pinker, R. T., D. Sun, M.-P. Hung, C. Li, and J. B. Basara, 2009: Evaluation of satellite estimates of land surface temperature 
from GOES over the United States. J. Appl. Meteor. Climatol., 48, 167-180, doi:10.1175/2008JAMC1781.1.

Prata, A. J., 1993: Land surface temperatures derived from the advanced very high resolution radiometer and the along-track scanning radiometer: 1. Theory. J. Geophys. Res., 98, 16 689-16 702, doi:10.1029/93JD01206.

Qin, J., K. Yang, S. Liang, and X. Guo, 2009: The altitudinal dependence of recent rapid warming over the Tibetan Plateau. Climatic Change, 97, 321-327, doi:10.1007/s10584-009-9733-9.

Scharlemann, J. P. W., D. Benz, S. I. Hay, B. V. Purse, A. J. Tatem, G. R. W. Wint, and D. J. Rogers, 2008: Global data for ecology and epidemiology: A novel algorithm for temporal Fourier processing MODIS data. PLoS One, 3, e1408, doi:10.1371/ journal.pone.0001408.

Schmid, H. P., 1997: Experimental design for flux measurements: Matching scales of observations and fluxes. Agric. For Meteor., 87, 179-200, doi:10.1016/S0168-1923(97)00011-7.

Schmidt, A., C. Hanson, W. S. Chan, and B. E. Law, 2012: Empirical assessment of uncertainties of meteorological parameters and turbulent fluxes in the AmeriFlux network. J. Geophys. Res., 117, G04014, doi:10.1029/2012JG002100.

Sobrino, J. A., and Y. Julien, 2013: Trend analysis of global MODISTerra vegetation indices and land surface temperature between 2000 and 2011. Selected Topics in Applied Earth Observations and Remote Sensing. IEEE J. Sel. Top. Appl. Earth Obs. Remote Sens., 6, 2139-2145, doi:10.1109/JSTARS.2013.2239607.

_- and M. Romaguera, 2004: Land surface temperature retrieval from MSG1-SEVIRI data. Remote Sens. Environ., 92, 247-254, doi:10.1016/j.rse.2004.06.009.

Sun, D., and R. T. Pinker, 2003: Estimation of land surface temperature from a Geostationary Operational Environmental Satellite (GOES-8). J. Geophys. Res., 108, 4326, doi:10.1029/ 2002JD002422.

Tomlinson, C. J., L. Chapman, J. E. Thornes, and C. Baker, 2011: Remote sensing land surface temperature for meteorology and climatology: A review. Meteor. Appl., 18, 296-306, doi:10.1002/met.287.

Wan, Z., 2006: MODIS land surface temperature products users' guide. Institute for Computational Earth System Science, University of California, Santa Barbara, 35 pp., https://icess. eri.ucsb.edu/modis/LstUsrGuide/MODIS_LST_products_ Users_guide.pdf.

- 2008: New refinements and validation of the MODIS land-surface temperature/emissivity products. Remote Sens. Environ., 112, 59-74, doi:10.1016/j.rse.2006.06.026.

_ retrieving land-surface temperature from space. IEEE Trans. Geosci. Remote Sens., 34, 892-905, doi:10.1109/36.508406.

, and Z.-L. Li, 1997: A physics-based algorithm for retrieving land-surface emissivity and temperature from EOS/MODIS data. IEEE Trans. Geosci. Remote Sens., 35, 980-996, doi:10.1109/36.602541.
— and - 2008: Radiance-based validation of the V5 MODIS land-surface temperature product. Int. J. Remote Sens., 29, 5373-5395, doi:10.1080/01431160802036565.

_ , Y. Zhang, Q. Zhang, and Z. L. Li, 2004: Quality assessment and validation of the MODIS global land surface temperature. Int. J. Remote Sens., 25, 261-274, doi:10.1080/0143116031000116417.

Wang, K., and S. Liang, 2009: Evaluation of ASTER and MODIS land surface temperature and emissivity products using longterm surface longwave radiation observations at SURFRAD sites. Remote Sens. Environ., 113, 1556-1565, doi:10.1016/ j.rse.2009.03.009.

—, Z. Wan, P. Wang, M. Sparrow, J. Liu, X. Zhou, and S. Haginoya, 2005: Estimation of surface long wave radiation and broadband emissivity using Moderate Resolution Imaging Spectroradiometer (MODIS) land surface temperature/emissivity products. J. Geophys. Res., 110, D11109, doi:10.1029/ 2004JD005566.

Wang, W., S. Liang, and T. Meyers, 2008: Validating MODIS land surface temperature products using long-term nighttime ground measurements. Remote Sens. Environ., 112, 623-635, doi:10.1016/j.rse.2007.05.024.

Williamson, S. N., D. S. Hik, J. A. Gamon, J. L. Kavanaugh, and S. Koh, 2013: Evaluating cloud contamination in clear-sky MODIS Terra daytime land surface temperatures using ground-based meteorology station observations. J. Climate, 26, 1551-1560, doi:10.1175/JCLI-D-12-00250.1.

,,,--- A. H. Jarosch, F. S. Anslow, G. K. C. Clarke, and T. Scott Rupp, 2017: Spring and summer monthly MODIS LST is inherently biased compared to air temperature in snow covered sub-Arctic mountains. Remote Sens. Environ., 189, 14-24, doi:10.1016/j.rse.2016.11.009.

Wu, P., H. Shen, L. Zhang, and F.-M. Göttsche, 2015: Integrated fusion of multi-scale polar-orbiting and geostationary satellite observations for the mapping of high spatial and temporal resolution land surface temperature. Remote Sens. Environ., 156, 169-181, doi:10.1016/j.rse.2014.09.013.

Yu, G., Y. Fu, X. Sun, X. Wen, and L. Zhang, 2006a: Recent progress and future directions of ChinaFLUX. Sci. China. Ser. D Earth Sci., 49, 1-23, doi:10.1007/s11430-006-8001-3.

$\longrightarrow$, X. Wen, X. Sun, B. D. Tanner, X. Lee, and J. Chen, 2006b: Overview of ChinaFLUX and evaluation of its eddy covariance measurement. Agric. For. Meteor., 137, 125-137, doi:10.1016/j.agrformet.2006.02.011.

Zhang, G., T. Yao, H. Xie, J. Qin, Q. Ye, Y. Dai, and R. Guo, 2014: Estimating surface temperature changes of lakes in the Tibetan Plateau using MODIS LST data. J. Geophys. Res. Atmos., 119, 8552-8567, doi:10.1002/2014JD021615.

Zhou, L., Y. Tian, S. Baidya Roy, C. Thorncroft, L. F. Bosart, and Y. Hu, 2012: Impacts of wind farms on land surface temperature. Nat. Climate Change, 2, 539-543, doi:10.1038/ nclimate1505. 